Chapter 7

\title{
Epigenome, Cancer Prevention and Flavonoids and Curcumin
}

\author{
Višnja Stepanić, Renata Novak Kujundžić and \\ Koraljka Gall Trošelj \\ Additional information is available at the end of the chapter \\ http://dx.doi.org/10.5772/58247
}

\section{Introduction}

Epigenome is a common name for heritable chemical modifications of DNA and histone molecules, of which DNA methylation and histone acetylation and methylation represent the most studied parts. Nucleosomes, the chromatin building units, are positioned in a way that is strictly dependent on the epigenome changes. Based on the presence of a specific epigenetic modification, the chromatin becomes less or more condensed. These changes in chromatin structure are inevitably related to gene activity. For example, DNA hypermethylation joined with histone hypoacetylation is frequently related to a condensed form of chromatin, marking the region of DNA that should not be active during a specific time window. This implies that genes in that specific region may become active once the aforementioned marks are removed. Indeed, epigenome represents a very powerful, extremely flexible "tool" for regulating gene activity and the major reason for the well-known phenomena of "time specific" and "tissue specific" gene expression.

In the field of cancer research, epigenome changes are considered to be among the first steps in carcinogenesis, preceding the structural changes in the DNA molecule, known generally as "gene mutations". Specifically, the most prominent change in the earliest phases of cancer is inactivation of tumor suppressor genes which are frequently silenced through DNA methylation and histone deacetylation taking place in the regions corresponding to their promoters. It is known that enzymes regulating these processes, DNA methyltransferases (DNMTs) and histone deacetylases (HDACs) are aberrantly up-regulated not only in a developed cancer, but also in the early phases of carcinogenesis (as recently shown for ductal in situ breast cancer [1]). Accordingly, significant effort has been given to the discovery and development of specific chemical compounds that may act as DNA demethylating agents and histone deacetylases 
inhibitors (HDACi). Some of these compounds are already utilized in the clinic, like DNMT inhibitors 5-azacytidine and decitabine and HDAC inhibitor vorinostat, with specific therapeutic indications [2]. In parallel with these research efforts, considerable data has been published on the role of natural compounds. The importance of these compounds has been intensely studied in the field of cancer prevention, especially in light of the influence of a specific diet on cancer prevention (as shown for the Mediterranean diet which may have a modest beneficial effect related to the incidence of colorectal carcinoma [3]). Many dietary compounds have been revealed to significantly impact gene expression through modulating the epigenome. Logically, if a specific type of diet is considered to be protective in relation to cancer, there has to be a molecular mechanism at the level of the epigenome explaining its protective effect.

These will be addressed in this book chapter, where we describe polyphenols' molecular mechanisms of action, through well-known compounds belonging to different chemical subgroups and shown in Table 1.

\section{Chromatin structure}

The native state of DNA, a double helix, is formed when two antiparallel strands are held together by hydrogen bonds (H-bonds) between complementary purine and pyrimidine bases. Each human diploid cell contains approximately two meters of DNA. Obviously, in order to be kept in the nucleus, which is, on average, nine micrometers in diameter, the DNA must be 10,000-20,000 folds compacted [4].

Histones are small proteins that act as chromatin "compacting units. The tight binding of DNA and histones is considerably dependent on the charge: DNA is negatively charged molecule due to presence of phosphate groups, and the strength of interaction between DNA and histones strongly depends on posttranslational modifications of histones' tails which can modify their charge. This is possible due to a specific structure of histone proteins. Histones' globular domain represents central part that is highly structured. In addition to this part, histone proteins have "tails" at both, $\mathrm{NH}_{2}$-and $\mathrm{COOH}$-ends. These tails may be modified through numerous types of posttranslational modifications of which methylation and acetylation will be discussed in detail through this chapter. These covalent modifications, by which cell regulates access to DNA, depend on enzymes often called "writers" and "erasers" [5].

\subsection{Histone modifications and gene transcription}

The part of the genome that contains genes that are dynamically transcribed must be shaped in an open, flexible way. Part of the chromatin that follows this rule is called euchromatin. Non-coding parts of genome, joined with those parts that contain inactive genes (e.g., in the region of centromeres and telomeres) do not need to follow significant reshape. This condensed, closed shape of chromatin is known as heterochromatin. So, how do histone modifications influence keeping these two forms of chromatin present in the cell and, also important, how do histone modifications influence "the switch" between the two forms? In other words, 


\section{Polyphenol}<smiles>O=c1c(O)c(-c2ccc(O)c(O)c2)oc2cc(O)cc(O)c12</smiles>

\section{Plant sources}

Apples, grapes, blackberries, cranberries, blueberries, onion, kale, capers, watercress, dill, bitter dock, red wines, black tea

Quercetin<smiles></smiles>

Tea, kale, carrot, capers, leek, celery, apples

Kaempferol<smiles>O=c1cc(-c2ccc(O)c(O)c2)oc2cc(O)cc(O)c12</smiles>

Sage, thyme, peppermint, carrot, broccoli, onion, chilli

Luteolin

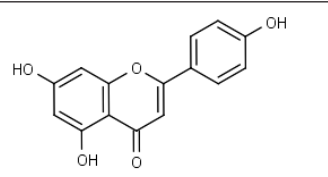

Chinese cabbage, parsley, papper, garlic, barley, endive, olive oil, chamomile, apples, onion

Apigenin

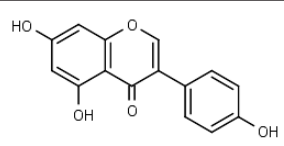

Soy, soy food - miso, tempeh, tofu etc.

Genistein<smiles>O=C(OC1Cc2c(O)cc(O)cc2OC1c1cc(O)c(O)c(O)c1)c1cc(O)c(O)c(O)c1</smiles>

Green tea

EGCG

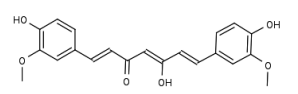

Turmeric (Curcuma longa), curry

Curcumin

Table 1. Structures and sources of selected polyphenols with known epigenome modifying activities. 
how is the need for expression of a specific gene during very short time period regulated by histone posttranslational modifications?

There are two basic mechanisms: a) direct, influencing the overall structure of chromatin, b) indirect, through the regulation of binding of effector molecules [6]. For example, trymethylation of lysine at the position 9 of histone 3 (H3K9me3) can recruit the protein HP1 (heterochromatin protein 1). The interaction takes place in the area of heterochromatin and leads to additional compacting that physically precludes access of transcriptional machinery [7]. There is sufficient level of evidence on cis-interactions in chromosome-mediated gene expression. For example, H3S10 phosphorylation enhances H3K4 methylation and H3K14 acetylation, and inhibits H3K9 methylation, thus indirectly facilitating chromatin decondensation [8].

The first report on histone acetylation is 50 years old [9]. The earliest studies following this discovery, revealed association of hyperacetylated histones with gene transcription [10]. In general, keeping in mind that there is no rule that would not have an exception, hyperacetylation of histone tails induces transcriptional activation, while hypoacetylation is associated with repression of transcription. Lysine acetylation is very dynamic process, regulated by antagonistic actions of two groups of enzymes: histone acetyltransferases (HATs) and HDACs. The consequence of lysine acetylation, which occurs upon the transfer of an acetyl group to the $\varepsilon$-amino-group of lysine side chain, is neutralization of lysine's positive charge and hence weakening interactions between histone and DNA. Mainly as a result of cumulative charge neutralizations at multiple lysines, the chromatin takes its "open", transcriptionally active structure [11]. This process is fast and happens in only a few minutes, as measured by isotopic pulse labeling [12]. In general, HDACs have the suppressing function, they are negative regulators of gene activity. It must be told that these enzymes have also many non-histone protein substrates that are included in regulation of important cellular processes, including cell proliferation and cell death. These are but not limited to: transcription factors, hormone receptors, cytoskeletal proteins, chaperons and various signaling mediators.

Histone methylation certainly is one of the best studied histone modifications, which takes place on both lysine and arginine amino acid residues. These modifications are not only residue-dependent (K4, K9, K27, K36, K79 in histone 3 (H3)) but also status-dependent (mono-, di-and trimethylation). In most scenarios, H3K4me2/3, H3K36me1/3 and H3K79me1/2 and $\mathrm{H} 4 \mathrm{~K} 20 \mathrm{~m} 1$ modifications are associated with activation of transcription, while H3K9me2/3, H3K27me2/3 and H4K20me3 marks are usually associated with transcriptional repression [13]. H3K4me3 association with 5' regions of active genes strongly correlates with overall transcription rate, active RNA polymerase II occupancy and global histone acetylation (reviewed in [14]). Such outcome is a consequence of binding of different proteins that specifically interact with activators or repressors of transcription.

Histone methylation depends on activity of histone methylating (histone lysine methyltransferases, KMTs) and demethylating (histone lysine demethylases, KDMs) enzymes. Both groups of enzymes have a very important role in cancer initiation and development and their mutations have been shown to exist in different types of malignant tumors. Methylation marks on histones are highly specific, altering gene expression in a way that may be unique for particular type of normal and/or cancer cell [13]. For example, histone demethylase KDM5A 
contains a highly specific $\mathrm{H} 3 \mathrm{~K} 4 \mathrm{me} 3$ reader domain and is probably involved in modifying nearby domains upon binding to H3K4m3. This enzyme was found to be present in regions that are enriched in $\mathrm{H} 3 \mathrm{~K} 4 \mathrm{me} 3$ and are transcriptionally active. This is particularly significant in cells originating from bone marrow and peripheral blood where high expression of its target genes was also found [13]. For that reason, the ratio of various histone demethylases and histone methyltransferases, KDM/KMT, was suggested to be a sign of a specific "transcription module", trying to predict expression of specific genes, members of specific module. This fact, which should provide more specific way of acting compared to acetylation balancing enzymes, makes enzymes involved in regulation of histone methylation status good candidates for specific epigenetic interventions.

Histone lysine methylation depends on KMTs that are classified into two groups, based on the sequence and structure of their catalytic domains: SET domain containing (suppressor of variegation homologus (SUV), enhancer of zeste proteins $(\mathrm{EZH})$, trithorax-group (TrxG) proteins) and non-SET domain containing (DOT1 protein family) [15].

So far, histone demethylases KDMs are grouped in two families. KDM1 family includes only two members, LSD1 (lysine-specific demethylase 1, KDM1A) and LSD2 (KDM1B). LSD1 was the first discovered histone demethylase and its discovery revealed that histone lysine methylation is reversible process [16]. LSD1 targets histone H3K4, and, when associated with androgen or estrogen receptor, it can also target histone H3K9. In addition, LSD1 has been shown to demethylate non-histone proteins, including tumor suppressor p53 and DNA methyltransferase-1 (DNMT1). The second, Jumonji C (JmjC) domain containing protein family, is numerous and includes seven subgroups with a total of $14 \mathrm{KDMs}$. There is no doubt that KDMs and KTMs must work coordinately in order to keep a precise regulation of histone methylation.

Both KDMs and KTMs are involved in cancer initiation and progression, although KDMs are much less studied. There are firm data on histone lysine methyltransferases expression change upon cell exposure to heavy metals. For example, peripheral blood mononuclear cells (PBMC) were isolated from the whole blood of healthy volunteers and exposed to varying concentration of nickel chloride $(0.25,0.5$ and $1.0 \mathrm{mM})$ for $24 \mathrm{~h}$ and compared to untreated control samples. The transcriptome analyses (Affymetrix Human Genome U133.20 Array) combined with ChipSeq with anti-H3K4me3, have revealed that there are 1381 entities with 2-fold difference in expression upon nickel exposure. This number was reduced to 382 and 246 with more stringent cuts off - 3-fold and 5-fold, respectively. The global level of H3K4me3 was increased. This study also showed that H3K4me3 does not occupy only the promoters of genes that were transcriptionally active, but also extends into their coding regions, as previously shown for nickel-exposed human lung adenocarcinoma cell line A549 [17]. When measured in PBMC from subjects that had occupational exposure to nickel but did not have cancer, the level of H3K4me3 was significantly increased when compared with PBMC from subjects without exposure [17]. Since chronic exposure to nickel has been associated with lung and nasal carcinoma, these results, obtained on human population, clearly show that harmful exposure indeed reshapes chromatin in a direction that leads to carcinogenesis. So, if detected 
early, before disease onset, can these changes be reversible? Even more so, can we influence the enzymes that reshape epigenome in a procarcinogenic direction?

\subsection{Interplay between DNA methylation and histone acetylation}

There are several chromatin-regulating factors that recognize methylated DNA or modified histone proteins. One of them, the HP1 protein, has already been mentioned. The common characteristic of these effector molecules is that they use a range of different recognition domains such as methyl-CpG-binding domains (MBD), zinc fingers ( $\mathrm{ZnF})$, chromo-domain, or plant homeodomain (PHD) in order to direct establishing specific epigenomic marks and orchestrate biological events $[18,19]$. However, the most of studies performed so far have been conducted using isolated DNA or histone peptides and cannot recapitulate the situation found in chromatin in vivo. Recently, an approach named SNAP (SILAC nucleosome affinity purification) was used for the identification of proteins that are influenced by DNA CpG methylation and histone H3 K4-, K9- or K27-methylation (or a combination thereof) in the context of a nucleosome. The approach itself seems to be very valuable in defining the chromatin "interactome" and showing that DNA methylation and histone modifications act in a concerted manner by creating a "modification landscape" that must be interpreted by proteins able to recognize large molecular assemblies [20].

This is not surprising due to the fact that there are currently 18 HDACs identified in humans, subclassified in four classes: a) class I HDACs 1, 2, 3 and 8 localized mainly in nucleus where they acetylate numerous proteins, of which p53 (cellular tumor antigen p53) and BRCA1 (breast cancer type 1 susceptibility protein) are probably the most frequently studied nonhistonic substrates; b) class II with class IIa of HDAC 4, 5, 7 and 9 isoforms located in nucleus and cytoplasm and class IIb of HDACs 6 and 10 located only in the nucleus; c) class III of sirutins SIRT1-7 whose activity depends on the presence of nicotinamide adenine dinucleotide $\left(\mathrm{NAD}^{+} / \mathrm{NADH}\right)$ and $\left.\mathrm{d}\right)$ class IV containing only one enzyme, HDAC11 [21].

Besides actions on histone molecules, the importance of modifying "the guardian of genome" p53 represents utmost important cellular event. One of the consequences of recruitment of HDAC1 to p53, through MDM2 (E3 ubiquitin-protein ligase), is p53 deacetylation and degradation. For this very reason, there is no p53-related induction of p21 ${ }^{\text {WAF1 }}$ (p21, cyclindependent kinase inhibitor 1) and MDM2 [22]. Luckily, p21 is not regulated only by p53, but also through many other transcription factors including Sp1 (transcription factor Sp1) for which six binding sites are present in the p53 promoter. Thus, this is only one example of multiple regulations and how complex the system has to be in keeping the balance of signals that will prevent cell from uncontrolled division, which is a hallmark of cancer.

HDACi are generally subdivided into several groups, based on their diverse chemical structures-short chain fatty acids, hydroxamates, cyclic peptides, aliphatic acids, benzamides, SIRT inhibitors, electrophilic ketones and miscellaneous compounds [23]. The member of the hydroxamate group, suberoylanilide hydroxamic acid (SAHA, vorinostat) has been approved by FDA in October of 2006 for treatment of a rare cutaneous T-lymphoma. The approval for the cyclopeptide, romidepsin (Istodax ${ }^{\circledR}$ ), came in November of 2009. Although well tolerated and with manageable side effects, HDACis have not entirely fulfilled expectations that were based on well-known molecular mechanism associated with their application in vitro: early 
studies have undoubtedly shown that these HDACis upregulate p21 in p53-independent fashion leading to G2/M cell cycle arrest [24]. Only two years later it was shown that this treatment additionally increases cyclin E and decreases cyclin D1 [25].

As expected, the problem lies in insufficient selectivity of HDACis: in addition to an increase of p21 and other pro-apoptotic genes, the treatment with HDACis also induces transcription of genes that are pro-carcinogenic, like multiple isoforms of protein kinase C (PKC) and downstream regulated matrix metalloproteinases (MMPs). Among 30 cancer cell lines (12 liver, 10 lung, 5 gastric and 3 breast cancer cell lines) that were tested for cell migration (indicating metastatic potential) after being treated with HDACis belonging to different groups (including vorinostat), 43\% (13/30) cell lines showed several hundred folds increase in migration potential [26]. This effect was initiated at low, non-cytotoxic sub- $\mu \mathrm{M}$ to low $\mu \mathrm{M}$ dosage of HDACis. In an in vivo experiment, tumor cell lines were injected into HDACi treated mice. In contrast to untreated control animals, these mice have developed metastatic disease with statistically proved significance $(p<0.026)$. However, when combined with curcumin or tamoxifen, this treatment had very promising effect both, in vitro and in vivo. Western blot analyses performed on tumor lysates obtained from mice treated with HDACi trichostatin A, combined with curcumin or tamoxifen revealed significant downregulation of PKCs and some other proteins included in tumor progression. Of importance, the high expression of p21 induced with HDACis remained unchanged.

It is well-known that dietary and other environmental factors induce epigenetic alterations. For example, smoking induces numerous harmful epigenetic alterations that can be first steps in malignant transformation. Accordingly, cellular epigenome may be protected from harmful events through a proper diet and healthy way of living.

With development of sophisticated methods applicable in all fields of molecular biology, anticancer properties have become proved for many natural compounds [27]. Their mode of action frequently influences cellular epigenome through chromatin remodeling [28]. For example, polyphenols can modulate chromatin structure through influencing expression of chromatin remodeling enzymes, HDACs and DNMTs [29]. Targeting these proteins in addition to various kinases (e.g. mitogen-activated protein kinases (MAPKs), phosphatidylinositide-3-kinase (PI3K), protein kinase B isozymes (AKT), Aurora B, Polo-like kinase 1 (PLK1)), poly(ADP-ribose) polymerase (PARP) and other epigenome modifying enzymes KDMs (LSD1, JMJD3) and HATs (p300/CBP (CREB binding protein) coactivators) [30] make them extremely powerful modifiers of cellular processes included in all aspects of cellular survival and cellular death. Besides, for all these multilevel ways of acting, affecting a large number of biochemical signaling pathways, natural polyphenols are excellent examples of polypharmacological compounds.

\section{Intracellular stability and nuclear localization of polyphenols}

In order to exert their effect on chromatin organization, polyphenols must be stable and able to enter cellular nucleus. There are numerous studies in the field of cancer research reporting 
on various changes in experiment-related pre-selected set of interesting proteins included in cellular proliferation, after adding a polyphenol to cellular medium. However, their intracellular accumulation, stability and transformation are poorly understood. This is not surprising, as there are only limited number of studies dealing with polyphenol's cellular uptake and efflux, their subcellular localization and intracellular stability [31]. These parameters are crucial for understanding their mechanism of action and biological effects.

The polyphenols are usually assumed to bind to cellular membrane and/or are in the cytosoplasm affecting membrane receptors and modulating kinases activity [32,33]. Polyphenols whose effects on chromatin are described in this review, may cross both cellular and nuclear membranes and enter nucleus. For example, quercetin has been shown to be localized mainly in the nucleus of HepG2 cells [34,35]. Flavon apigenin has been reported to localize mostly in nuclear matrix and less in cytosol, nuclear membranes and microsomes of prostate cancer cell lines DU145, LNCaP and PC-3 [36]. By using a confocal laser scanning fluorescence microscope, the autofluorescence of galangin and kaempferol appeared stronger in the nucleus than cytoplasm of mouse hepatoma Hepa-1c1c7 cells [37]. Among flavonoids, only flavonols containing the conjugated 3-OH group (Figure 1), show autofluorescence and can be detected by this approach. The highest percentage of curcumin in breast cancer cell line MCF-7 cells has been found in membrane and decreases in the following order: membrane > cytoplasm > nucleus $>$ mitochondria [38]. The fluorescent conjugates of EGCG were localized onto the membrane as well as in the cytoplasm and nucleus of mouse fibroblasts L-929 [39], but are found on the membrane, in the cytoplasm and specifically in mitochondria of the human umbilical vein endothelial cells (HUVECs) [40]. The largest fraction of soy isoflavone genistein has been localized in cytoplasm, but it has also been registered in nuclei and mitochondria of pooled female rat liver [41]. The associated concentrations of genistein were in the $\mathrm{nmol} / \mathrm{g}$ range, far below the concentrations required for most of its in vitro effects [41]. Concentrations of parent polyphenols within cells in vitro are usually in low $\mu \mathrm{M}$ to sub- $\mu \mathrm{M}$ range [42].

Namely, significant portion of a polyphenol, such as in the cases of EGCG [43] and apigenin [44], may be intracellularly transformed, depending on cell type and cell culture conditions, particularly $\mathrm{pH}$ of the medium $[43,45]$. At the cellular level, metabolic transformations of polyphenols through phases I and II enzymes, have been well-documented, including hydroxylation by CYP450 isoforms CYP1A2, CYP3A4 [44] and CYP1B1 [46] and methylation of hydroxyl groups by catechol-O-methyl transferase (COMT) [31]. These reactions may be necessary for generation of active metabolites, as is the case with conversion of apigenin into its main metabolite, luteolin [47]. Furthermore, since polyphenols more or less readily participate in redox processes, the contribution of their oxidized quinone/quinone methide forms to their mechanisms of action may not be excluded [48], particularly when relatively high concentrations of flavonoids (high $\mu \mathrm{M}$ to $\mathrm{mM}$ ) have been applied to cells [31].

Metabolic conjugation alters the physicochemical properties of flavonoids and it is widely assumed that this can affect their biological activity. Hence, for understanding the cellular effects of parent polyphenol compounds, the influence of their uptake, intracellular metabolism, oxidation and localization should be taken into account or a priori excluded [49]. This is enormously important when put in the context of cellular epigenome which is specific for each 
type of cell. It may not be surprising then that specific effects of metabolites are consistent with findings that polyphenols' actions are cell-type dependent.

As usual, observations presented in this review will be interpreted in terms of parent polyphenol aglycons whose structures are shown within Table 1, but one should bear in mind that they may be exerted by their metabolites and oxidized forms.

\section{Dose-dependent effects of polyphenols}

The cellular effects of polyphenols recorded in vitro are concentration- and time-dependent $[49,50]$. Application of quercetin and EGCG as well as other polyphenols like resveratrol, induces hormetic dose-response cellular phenomenon characterized by a low-dose stimulation and high-dose inhibition, often resulting in typical U-or J-shaped curves [50]. While showing pro-oxidant properties joined with citotoxicity at high concentrations, low doses of quercetin (1-40 $\mu \mathrm{M})$ were shown to have antioxidant and chemopreventive properties [51]. Also, application of curcumin, even at a very low concentration $(10 \mu \mathrm{M})$, and especially if exposure was prolonged (up to $72 \mathrm{~h}$ ), was shown to be cytotoxic for various cancer cells, but not for fibroblasts WI-38 [52].

At the low $\mu \mathrm{M}$ doses, the polyphenols activate hormetic adaptive cellular stress response signaling pathways that include various kinases and transcription factors [50]. As a result, there is an activation of genes that encode stress resistance proteins such as antioxidant and detoxifying enzymes, protein chaperones, neurotrophic factors, and other cytoprotective proteins. Specific example of such a pathway is the Nrf2/ARE (NF-E2-related factor 2 / antioxidant response element) pathway [50]. At these concentrations, these compounds are not cytotoxic, but cytostatic. They commonly block the cell cycle in various cancer cells in S/G2 and mitotic phase, leading to cell death. They also target multiple kinases that are implicated in pathogenesis of cancer.

\section{Plant polyphenols in cellular growth arrest and death}

So far, all studied polyphenols have been shown to induce both, apoptosis and autophagy of cancer cells, without affecting normal cells $[53,54,55]$. Epicatechin and quercetin have been shown to stimulate autophagy by simultaneous promotion of cytoplasmic protein deacetylation although with different potencies and, possibly, through distinct molecular pathways [53]. Selected polyphenols can induce G0/G1 (growth arrest effect) and / or G2/S (anti-mitotic effect) phase cell cycle arrest of various human cancer cell lines [56]. The induction of autophagy and apoptosis is a very important mechanism for cancer prevention by dietary polyphenols. It represents an effective anti-cancer strategy since it is based on an effort to block or suppress the multistage process of carcinogenesis which relates to six fundamental hallmarks of cancer: self-sufficient proliferation, insensitivity to anti-proliferative signals, evasion of apoptosis, unlimited replicative potential, maintenance of vascularization, and, finally, tissue invasion 
and metastasis [57,58]. In addition, chemoprevention based on dietary polyphenols is not expected to be accompanied by side effects since they are selectively toxic for the cancer cells.

Mechanistically, polyphenols have been shown to induce growth arrest and increase apoptosis in cancer cells in various ways. Antiproliferative effects of dietary polyphenols are generally associated with their capacity to regulate response to oxidative stress and/or DNA damage, suppress angiogenesis, and inhibit various pro-proliferative signaling pathways. They affect all aspects of carcinogenesis at its different stages through inhibition of various survival transduction pathways related to NF- $\mathrm{B}, \mathrm{PI} 3 \mathrm{~K}, \mathrm{AKT}$ and MAP kinases, as well as by stimulating expression of tumor suppressor genes (p53, BRCA1 and BRCA2) [57,58]. All polyphenols studied so far, except apigenin, are able to modify redox cellular state as potent radical scavengers [59]. They are also direct inhibitors of enzymes included in production of reactive endogenous radicals. In addition to the effect on their enzymatic activity, dietary polyphenols are also modulators of expression of proteins related to cellular antioxidant defenses and detoxification, often through regulation of transcriptional activity of Nrf2.

These multiple effects of dietary polyhenols have been reviewed many times so far. Here, we are focused on reviewing recent studies of some polyphenols' influence on alteration of gene expression through modulating epigenome by affecting DNA methylation and posttranslational modifications of histone proteins. Natural compounds seem to offer a huge source of epigenetically active compounds of which flavonoids - flavonols quercetin and kaempferol, flavones apigenin and luteolin, isoflavone genistein, catechin EGCG and curcuminoid curcumin certainly take a very important place.

\section{Quercetin}

Quercetin is strong natural antioxidant flavonol ubiquitously present in dietary plant sources (Table 1) [59]. Cellular sensitivity and specific response to quercetin depends on sensitivity to hydrogen peroxide, $\mathrm{H}_{2} \mathrm{O}_{2}$. For example, quercetin induces formation of 8-oxo-7,8-dihydro-2'deoxyguanosine (8-oxodG), an indicator of oxidative DNA damage, in HL-60 cells, while in their $\mathrm{H}_{2} \mathrm{O}_{2}$-resistant clone, HP 100 cells, this effect does not occur [60]. This, again, shows that mode of action of specific nutraceuticals depends on cellular "molecular background".

In addition to its substantial redox activity, quercetin has multiple intracellular molecular targets, affecting different signaling processes that are altered in cancer cells, with limited or no toxicity against normal cells. Accordingly, quercetin inhibits carcinogenesis primarily through inhibition of pro-proliferative signaling pathways. It has been found to be a pleiotropic kinase inhibitor [61]. At $2 \mu \mathrm{M}$ concentration, quercetin was shown to decrease the activity of 16 recombinant kinases by more than $80 \%$, including ABL1, Aurora-A,-B,-C, CLK1, FLT3, JAK3, MET, NEK4, NEK9, PAK3, PIM1, RET, FGF-R2, PDGF-R $\alpha$ and -Rß [62]. Many of these kinases are positive regulators of cell cycle. Thus, through simultaneous targeting of multiple pathways related to these kinases, quercetin may act as antiproliferative agent [61].

Part of quercetin's effects has been attributed to its ability to influence histone acetylation (Figure 1). Quercetin was reported to block the binding of different transactivators including 


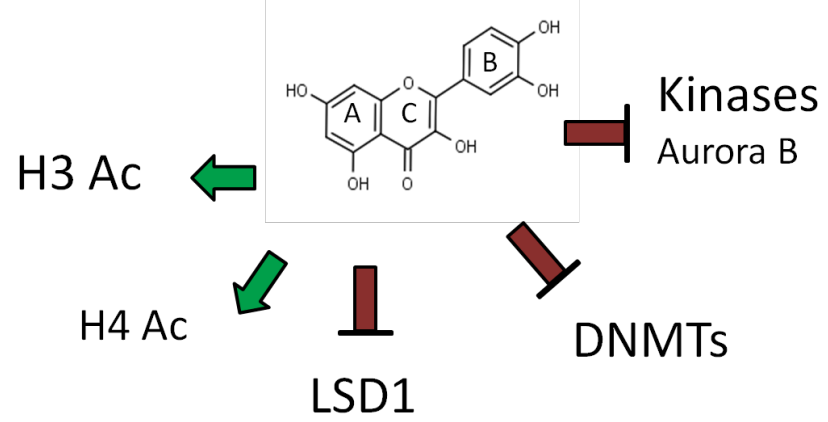

Figure 1. Epigenetic factors modulated by quercetin. Ring and atom annotations of 2-phenyl-1,4-benzopyrone scaffold.

p300, CREB2, c-Jun, C/EBP $\beta$ and NF- $\kappa \mathrm{B}$ to to the promoter of proinflammatory gene, COX2 (cyclooxygenase-2) [63]. As a consequence, there is a decrease in the level of the COX-2 protein. Generally, COX-2 decrease is considered to be a very beneficial step to a successful cancer chemoprevention $[63,64]$. While there is no doubt that quercetin affects numerous signaling pathways, one of these was well-explained on mouse intestinal epithelial cell line MODE-K, through its inhibitory effect on Akt phosphorylation, but without affecting cytoplasmic IKK (inhibitor of nuclear factor kappa-B (IкB) kinase) activity. Thus, in this experimental model, quercetin had no direct effect on NF- $\kappa \mathrm{B}$ activation. Instead, it inhibited recruitment of the NF$\kappa \mathrm{B}$ cofactor $\mathrm{p} 300 / \mathrm{CBP}$ to the promoters of inflammatory genes IP-10 (10 kDa interferon gammainduced protein, C-X-C motif chemokine 10) and MIP-2 (WD repeat-containing protein 26), through modulation of histone $\mathrm{H} 3$ acetylation and phosphorylation [65]. At $5 \mu \mathrm{M}$ concentration, quercetin was reported to increase acetylation of histones $\mathrm{H} 3$ and $\mathrm{H} 4$ induced by trichostatin A in A549 (expressing wild-type p53) and H1299 (a p53 null mutant) lung cancer cell lines, through p53 independent pathway [66].

Quercetin has also been found to effect activity of class III histone deacetylases SIRTs. Due to the fact that biological effects of polyphenols depend on their own chemical stability and metabolism, it is sometimes hard to predict whether in vitro test results may precisely predict the situation in the living organism, in vivo. For example, it has been observed that quercetin increases deacetylase activity of recombinant SIRT1, but at cellular level it inhibits SIRT1 activity [67]. This has been explained by metabolic transformation of quercetin. When quercetin's metabolite, quercetin-3-O-glucuronide, was taken instead of quercetin, an inhibitory function on recombinant SIRT-1 was shown. However, quercetin activates SIRT1 deacetylase activity in hypoxia-exposed or hypoxic preconditioned HepG2 cells similarly to resveratrol, resulting in hypoxic down-regulation of $c-M y c$ and $\beta$-catenin [68].

Sirtuins affect the acetylation status of histones as well as other important cellular non-histone proteins like HIF-1 $\alpha$, c-Myc and $\beta$-catenin [68]. SIRT1-mediated histone deacetylation (H1K26, H3K9, H3K14, H4K16) is associated with the formation of heterochromatin. On the other hand, SIRT1 interacts with numerous transcription factors and, through modifying their acetylation 
status, modifies their function. For example, in the presence of stress stimuli, SIRT1 deacetylates p53 and FOXO3 (forkhead box protein O3) leading to inhibition of apoptosis [69]. Another mechanism for inhibition of stress-induced apoptosis is through deacetylation of repair factor Ku70 (X-ray repair cross-complementing protein 6) and consequential sequestration of the proapoptitic factor BAX (Bcl-2-associated X protein) away from mitochondria [70]. While SIRT1 is capable of protecting cells from p53-induced apoptosis, its activity augments apoptosis in response to TNF- $\alpha$ (tumor necrosis factor alpha) by deacetylating RelA/p65 at lysine 310 and thus supressing transcription of NF- $\kappa$ B regulated genes [71].

Quercetin has been found to affect other class III HDAC, SIRT6, in vitro. Using frontal affinity chromatographic techniques, it has been found to inhibit deacetylase activity of immobilized recombinant SIRT6 protein against H3K9 [72].

Quercetin effects have been mostly studied on blood cancers. It induces apoptosis and autophagy of human leukemia HL-60 cells through orchestrating various signaling pathways and chromatin remodeling [73]. It has been reported to induce significant histone hyperacetylation at concentrations 75 and $100 \mu \mathrm{M}$ in human leukemia cells, indicating the possible involvement of histone hyperacetylation in its in vitro anticancer activity $[73,74]$.

Quercetin has also been found to influence DNA as well as protein methylation levels. Hypermethylation of the tumor suppressor gene $p 16^{\text {INK4a }}(\mathrm{p} 16$, cyclin-dependent kinase inhibitor 2A) in human colon cancer cell line RKO was successfully reversed after $120 \mathrm{~h}$ of treatment with quercetin [75]. This effect was concentration dependent.

Quercetin inhibiting activity against demethylase LSD1 was shown recently [76]. LSD1, commonly upregulated in cancer, has critical role in controlling the transcription of genes involved in cell growth and differentiation [77], and its inhibition may have significant therapeutic value. LSD1 functions primarily in multiprotein complexes, which includes, for example, HDAC1/2 and SIRT1.

Quercetin, as well as other catechol polyphenols, may indirectly inhibit DNMTs and thus DNA methylation, through changing intracellular concentrations of S-adenosyl methionine (SAM) and S-adenosyl-L-homocysteine (SAH) in a manner illustrated in Figure 2 [78].

\section{Kaempferol}

Kaempferol is a flavonol found in various vegetables (Table 1). In comparison with quercetin, it has considerably lower antioxidant capacity due to missing catechol moiety [59]. It possesses only 4'-OH group at ring B (Figure 1). However, like quercetin, kaempferol has a wide range of pharmacological activities, including antioxidant, anti-inflammatory and anticancer activity [79]. It suppresses growth of a number of human cancer cell lines in a concentration-dependent manner, through inducing an arrest in G0/G1 or G2/M phases of cell cycle [80]. Depending on the type of the cell, kaempherol can induce apoptosis [81,82] and autophagy [80]. For example, it induces apoptosis of human breast cancer cells MCF-7, by initiation of intrinsic caspase 


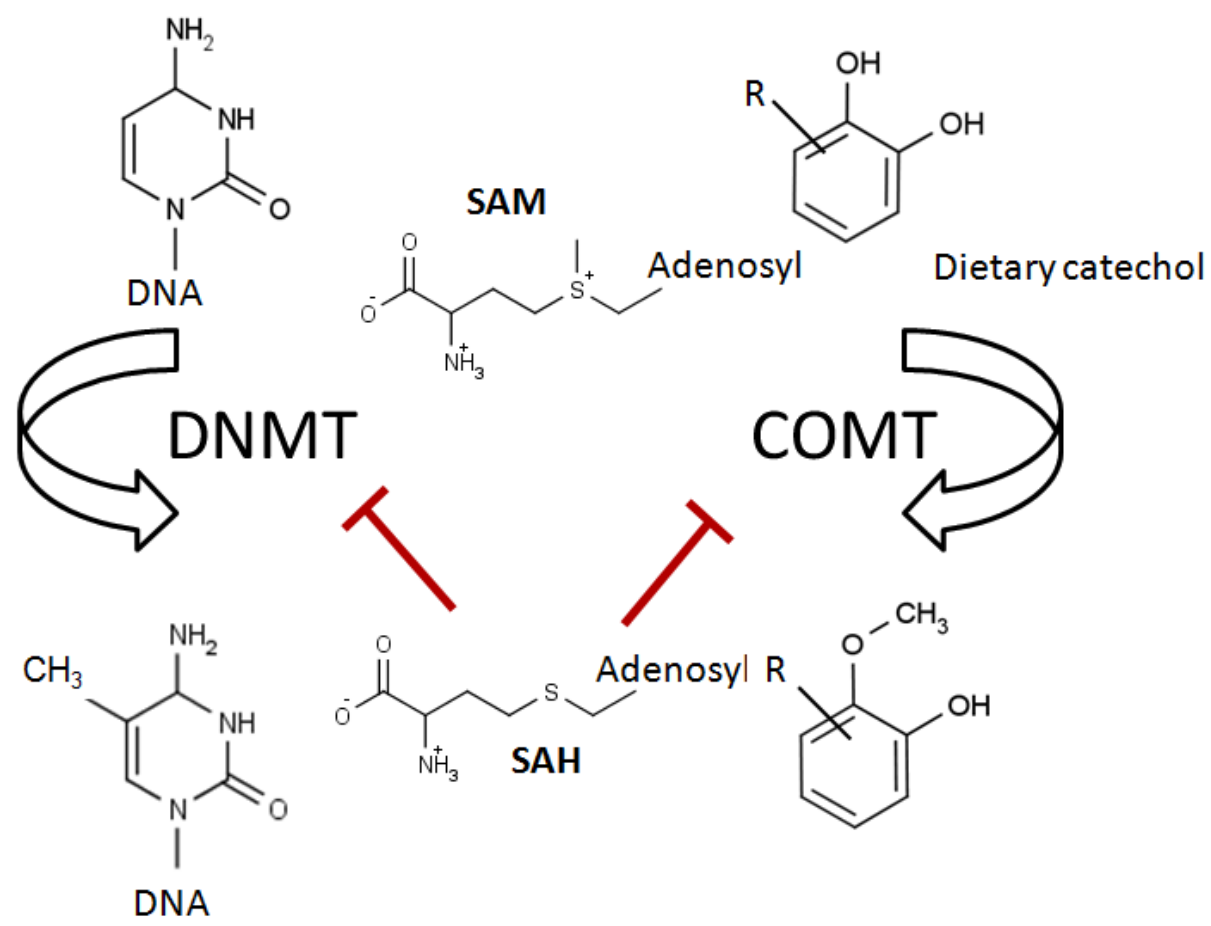

Figure 2. Indirect inhibitory effect of polyphenols with catechol (quercetin, luteolin) or galloyl (EGCG) moiety on DNMTs activity. In the O-methylation process of these polyphenols catalysed by the enzyme COMT, DNMT co-factor SAM is transformed into SAH which inhibits DNMTs and COMT.

cascade and down-regulation of the expression of nuclear kinase PLK1, an early trigger for G2/M transition and mitotic progression [83].

In human liver and colon cancer cell lines (HepG2, Hep3B, HCT-116) kaempferol (5-100 $\mu \mathrm{M})$ was shown to induce a prominent reduction of cell viability and proliferation rate, partly mediated through induction of hyperacetylation of histone $\mathrm{H} 3$ complex [81]. By performing in silico molecular docking analysis and in vitro profiling on these cancer cell lines, kaempferol has been recognized as a pan-inhibitor of human HDACs of classes I, II and IV [81].

Treatment of the chronic myelogenous leukemia cell line K562 and promyelocitic human leukemia U937 with $50 \mu \mathrm{M}$ kaempferol resulted in inhibition of PI3K and dephosphorylation of Akt at Ser473 and Thr308 as well as in an increase of the expression of deacetylase SIRT3 and its mitochondrial localization [84]. Finally, apoptotic death of these cells upon kaempferol exposure was a consequence of the induction of mitochondrial phase of the apoptotic program with an aforementioned increase of SIRT3, joined with an increase of BAX, decrease of Bcl-2, release of cytochrome c, and caspase-3 activation. Kampferol was also shown to be an inhibitor of recombinant SIRT6 activity [72]. 
Similar to quercetin, kaempferol has shown inhibitory effect on histone demethylase LSD1 [76]. This enzyme has been reported to inversely regulate expressions of iodothyronine deiodinases of type 2 (D2) and type 3 (D3), acting as a molecular switch that dynamically finely tunes cellular needs for active thyroid hormone during myogenesis [85]. Kaempferol has been known to interfere with many aspects of the thyroid hormones synthesis [86]. LSD1 relieves the repressive marks $(\mathrm{H} 3 \mathrm{~K} 9 \mathrm{me} 2 / 3)$ on the DIO2 promoter and the activation marks (H3K4me2/3) on the DIO3 promoter. This action is well-orchestrated and depends on LSD1 interaction with transcription factor FoxO3. When FoxO3 binding to DNA is abrogated, LSD1 cannot induce D2.

\section{Luteolin}

Luteolin is a flavone widely distributed in the plant kingdom (Table 1). In difference to quercetin, it misses conjugated 3-OH group in C-ring (Figure 1) which considerably contributes to high radical scavenging capacity of quercetin [87]. Accordingly, luteolin is less efficient radical scavenger than quercetin [59]. However, the rest of structures of luteolin and quercetin are similar and hence similar biological activities have been observed. Both flavonoids have $3^{\prime}$-, 4'-catechol moiety in B-ring, resorcinol-like A-ring and extended $\pi$-electron delocalisation through whole skeleton. Luteolin inhibits growth of various cancer cell lines in a concentrationdependent manner [88]. The most common effect induced with luteolin, as well as other studied polyphenols with resorcinol-like structure of A-ring, is G2/M arrest of the cell cycle [88]. However, underlying mechanisms of action vary among flavonoid family members, primarily due to different number and positions of other hydroxyl groups at a common flavone (2-phenyl-1,4-benzopyrone) backbone, leading e.g. to different antioxidant capacities and intracellular metabolic transformations. The difference in antioxidative capacity of considered flavonoids may be relevant for the observed differences in biological activities as well as molecular mechanisms of action. For example, as quercetin, luteolin induces apoptosis in HL-60 cells [60]. However, luteolin acts in non-oxidative way via forming a luteolin-topoisomerase II-DNA ternary complex and thus mediates DNA cleavage.

In addition to modulation of cellular redox level and inhibition of topoisomerases I and II, the underlying antiproliferative activities of luteolin relate to suppression of cell survival pathways including those related to PI3K/Akt, NF- $\kappa B$ and X-linked inhibitor of apoptosis protein (XIAP). It also stimulates apoptotic pathways, including those that depend on the induction of the $p 53[89,90]$.

Luteolin also inhibits recombinant LSD1 in vitro [76]. Actually, due to the sequence homology between LSD1 and monoamine oxidases (MAO) catalytic domains, some synthetic MAO inhibitors such as trans-2-phenylcyclo-propylamine (TCP) and well-known natural MAO inhibitors [91,92] including luteolin, quercetin and curcumin (but not EGCG and apigenin) have been detected as potent inhibitors of LSD1 [76]. Since TCP treatment of embryonic kidney cell line HEK293 increases SIRT1 at the protein level (without recordable effect on SIRT1 mRNA level), the potent natural LSD1 inhibitors may be also expected to elevate the level of SIRT1 protein. 
As measured with colorimetric HDAC Activity Assay Kit, luteolin at $50 \mu \mathrm{M}$ inhibited total HDAC activity joined with increased acetylation of histones $\mathrm{H} 3$ and $\mathrm{H} 4$. No doubt, this finding suggests that this dietary flavonoid plays an important role in regulation of gene expression and, consequentially, has an inhibitory effect on growth of various tumor cells (LNM35, HT29, HepG2, MCF7/6 and MDA-MB231-1833) [93].

The resorcinol-like A ring was also found to be a part of flavonoid pharmacophore accounting for SIRT6 inhibition. Accordingly, luteolin inhibits deacetylase activity of recombinant SIRT 6 against H3K9 [72]. Furthermore, since luteolin is also the substrate of COMT [94], it may indirectly inhibit DNMTs by elevating endogenous SAH concentration (Figure 2) [78].

Histone $\mathrm{H} 3$ phosphorylation (H3S10) is a result of Aurora kinase B activity. This specific epigenetic mark is the hallmark of mitosis. Similar to quercetin [62], luteolin inhibits recombinant Aurora B enzymatic activity (equilibrium dissociation constant $K_{D} 5.85 \mu M$ ) [95]. Its inhibitory effect on endogenous Aurora B activity in different cancer cell lines was also documented [95]. The consequence of this inhibition, which was shown to be dose-dependent, is down-regulation of H3S10 phosphorylation after $24 \mathrm{~h}$ treatment. Inhibition of Aurora B kinase activity was also observed for fisetin and 3-hydroxyflavone [95], indicating that this effect may be related to common 2-phenyl-1,4-benzopyrone backbone (Figure 1).

In addition to inhibiting Aurora B kinase activity and hence reducing $\mathrm{H} 3$ phosphorylation (Figure 3), luteolin has been found to decrease the acetylation status of histone $\mathrm{H} 4$ at the promoter of the pro-proliferative kinase PLK-1 in PC-3 cells [88], leading to transcriptional silencing of this oncogene [83].

Luteolin is a ligand for the nuclear type II [(3)H]estradiol binding site-a binding domain on histone $\mathrm{H} 4$ [88]. Although, it has also been reported to stimulate c-Fos and p21 and inhibit the cell cycle pathway genes, these changes are considered to be only supportive factors in regulation of proliferation. The data obtained so far suggest that type II ligands, including luteolin, inhibit cell growth and proliferation through epigenetic control of key genes involved in cell cycle progression [88].

\section{Apigenin}

Apigenin is a flavone ubiquitously present in vegetables and fruits (Table 1). It induces cell cycle arrest, p53-dependent apoptosis as well as autophagy of different cancer cells. Like other polyphenols, apigenin is selectively toxic to cancer cells. However, it is much weaker radical scavenger when compared to already described flavonoids [59]. Its mechanism of action depends on cancer cell type, indicating possible existence of structural modifications caused by cellular metabolism. For example, apigenin $(50 \mu \mathrm{M})$ blocks cellular proliferation through G2/M phase arrest of myeloid HL60 cells, leading to caspase-dependent apoptosis [96]. In contrast, it $(100 \mu \mathrm{M})$ blocks erythroid TF1 cells in G0/G1 phase leading to autophagy. In both cell lines the JAK/STAT pathway was one of major apigenin targets. 
Treatment of monocytic leukemia cells THP-1 with apigenin $(50 \mu \mathrm{M})$ induced DNA damage mediated by kinases PKCס and p38 [97]. The cell cycle progression at G1/S was delayed and joined with the increased number of apoptotic cells. The PKCS-dependent phosphorylation of ataxia-telangiectasia mutated (ATM) kinase and histone $\gamma \mathrm{H} 2 \mathrm{AX}$ (a marker of double strand DNA breaks) upon treatment with apigenin, resulted in transcriptional down-regulation of genes involved in cell-cycle control and DNA repair. This indicates that THP-1 cells may be unable to repair DNA damage induced by apigenin, hence triggering apoptosis.

Exposure of LNCaP (hormone-dependent / p53 wild type) and PC-3 (hormone-independent / p53 mutant type) prostate cancer cells to apigenin (and also genistein, see next section) resulted in same pattern of cell cycle arrest and apoptosis, associated with p21 up-regulation and PLK1 suppression [98].

Apigenin $(20-40 \mu \mathrm{M})$ treatment of prostate cancer cells PC-3 and 22Rv1 resulted in the inhibition of HDACs of class I, particularly HDAC1 and HDAC3, at the mRNA and protein levels [99]. Apigenin-mediated HDAC inhibition resulted in reversal of aberrant epigenetic events that promote carcinogenesis, that is, in global histone $\mathrm{H} 3$ and $\mathrm{H} 4$ acetylation, as well as localized hyperacetylation of histone $\mathrm{H} 3$ on the $p 21$ promoter. A corresponding increase in $\mathrm{p} 21$ and BAX mRNA and protein expressions resulted in cell cycle arrest and induction of apoptosis in both cell lines. This effect was additionally demonstrated in vivo by studies of PC-3 xenografts in apigenin-fed athymic nude mice.

Like already described flavonoids, arginin modulates recombinant SIRT6 deacetylase activity although more weakly than quercetin [72].

\section{Genistein}

Genistein is an isoflavone abundant in soybeans. Genistein represents a prototype of a phytoestrogen able to bind to nuclear hormone receptors ER- $\alpha$ and ER- $\beta$. It also downregulates androgen receptor in androgen-dependent prostate cancer cell lines such as LNCaP [100]. It has been investigated as a chemopreventive agent against various cancers, particularly hormone-responsive breast and prostate malignancies. According to numerous in vitro experimental results accompanied with in vivo models, it displays pro-apoptotic, antimetastatic and antiangiogenic properties.

Genistein is only moderately strong radical scavenger [59]. However, this isoflavone exerts antioxidant effects on cellular level at low $\mu \mathrm{M}$ concentrations, which correspond to physiologically relevant concentrations in plasma. The plasma level of genistein in women consuming soy products was observed to be $0.74-6.0 \mu \mathrm{M}$ [101]. Already at concentration of $0.5 \mu \mathrm{M}$, genistein increases antioxidant status of cells via i) interaction with estrogen receptors, ii) activation of ERK1/2 and iii) nuclear translocation of p50 subunit of NF- $\kappa B$, resulting in an overexpression of MnSOD (manganese-dependent superoxide dismutase) and consequential lowering of intracellular peroxide levels [102]. 
Genistein can arrest cell growth and induce apoptosis in various hematological cancer cell lines [103] and cell lines of solid tumor origin (e.g. HCT-116 and SW-480 [104]). Its influence on modulation of cell cycle most commonly relates to induction of G2/M cell cycle arrest, as shown in breast, colon, malignant glioma and prostate cancer cell lines [104,105,106]. At a molecular level, this effect is commonly dependent on tumor suppressors p53, p21 and/ or p16 [106].

While genistein's anticancer effects appears similar in different cancer cell lines, the underlying molecular mechanism of its action depends on a cell type. For example, genistein was shown to have a strong inhibitory effect on cellular growth followed by apoptosis, on two different prostate cancer cell lines, LNCaP-androgen-sensitive and DuPro - androgen resistant. However, it induced G0/G1 and G2/M cell cycle arrest in LNCaP and DuPro cells, respectively [107]. In addition, cellular effects of genistein on cancer cell cycle are very dependent upon applied dose [103].

Genistein has been one of the first specific protein tyrosine kinase inhibitors which was described almost 30 years ago [108,109]. As already stated, genistein antagonizes estrogen-and androgen-mediated signaling pathways [106]. It has also been found to intervene in other cellular signal transduction pathways inhibiting carcinogenesis through inhibition of NF- $\kappa \mathrm{B}$ and Akt signaling $[57,109]$. Significant part of genistein's action, including growth inhibition and cytotoxicity, relates to its inhibitory effect on topoisomerase II. This was very clearly shown through resistance to genistein in a model of murine transgenic cells lacking topoisomerase II beta $[110,111]$.

Besides, genistein is also a potent modifier of epigenetic events including DNA methylation and/or histone acetylation - directly, or through steroid receptor dependent process [101]. In both aforementioned prostate cell lines, LNCaP and DuPro, genistein treatment $(10-25 \mu \mathrm{M})$ reshaped the chromatin structure [107]. The treatment increased acetylation level of histones $\mathrm{H} 3$ and $\mathrm{H} 4$ at the transcription start sites of the two tumor suppressor genes, $p 21$ and $p 16$. It also increased expression of transcriptional activators HATs, but did not change the global methylation status of these cells.

Genistein's effect on breast cancer cells is selective as shown recently [112]. In a dosedependent manner genistein inhibits both precancerous (normal human mammary epithelial cells stably transfected with SV40 and human telomerase reverse transcriptase, hTERT) and cancerous breast cells growth. Of importance, the apoptotic process was more prominent in precancerous than in cancerous breast cells, indicating the strong preventive potential. At the same time, there were only minor effects when applied to (commercially available) normal mammary epithelial cells [112]. In vivo, orthotopic breast cancer mouse model was used. The animals were orally-fed with genistein enriched diet (modified AIN-93G diet supplemented with $250 \mathrm{mg} / \mathrm{kg}$ genistein, corresponding to high-soy diet in humans). In these animals, genistein has inhibited breast cancer growth; the tumors had considerably lower wet weight and significantly less PCNA (proliferating cell nuclear antigen) positive cells, when compared with tumors that were developed in the animals fed with diet that was not supplemented with genistein. At the mRNA level, there was a strong increase in expression of tumor suppressor genes $p 16$ and $p 21$, and dramatic decrease of oncogenes BMI1 (polycomb complex protein BMI-1) and $c-M Y C$. These changes in mRNA 
expression clearly point out genistein's effect on epigenome. Indeed, this was confirmed in experiments that showed that genistein induces formation of euchromatine in the region that covers promoters of $p 21$ and $p 16$, through changing the ratio of activating and repressive histone modifications. Specifically, genistein treatment increased histone $\mathrm{H} 3$ acetylation and formation of $\mathrm{H} 3 \mathrm{~K} 4 \mathrm{me} 3$ and, at the same time, decreased formation of suppressive chromatin marks, H3K9me3 and H3K27me3 [112]. These changes were mild in breast cancer cells, but very prominent in precancerous breast cell line, indicating, one more time, the importance of genistein in the process of cancer prevention. Based on several scientific reports, especially in the field of breast cancer, it seems that genistein significantly influences KTMs, while its effect on HDACs does not seem to be so prominent [112].

In breast cancer cell lines MCF-7 (ER- $\alpha$ positive) and MDA-MB 231 (ER- $\alpha$ negative) genistein $(18.5 \mu \mathrm{M})$ induces decrease in trimethylated marks at H3K27, H3K9 and H3K4, at six selected genes: EZH2 (histone-lysine N-methyltransferase that adds methyl group to H3K27), BRCA1, ER- $\alpha$, ER- $\beta$, SRC3 (steroid receptor coactivator protein 3, that displays HAT activity) and p300 [113]. Genistein treatment also affected histone acetylation marks in close proximity of these six selected genes recorded as an increase in $\mathrm{H} 4 \mathrm{~K} 8 \mathrm{ac}$ and $\mathrm{H} 3 \mathrm{~K} 4 \mathrm{ac}$ modifications.

In MDA-MB-231 cells, genistein $(25 \mu \mathrm{M})$ restored ER- $\alpha$ expression by remodeling the chromatin structure in the $E R-\alpha$ promoter $[112,114,115]$. This is very beneficial effect, as it increases tamoxifen-dependent anti-estrogen therapeutic sensitivity in vitro and in vivo. In addition, this effect was synergistically enhanced when combined with HDACi trichostatin A.

There are also experimental data on genistein's effect on colon cancer cells. When applied to HT29 cell line, genistein has been reported to have inhibitory effects on HDAC activity with $\mathrm{IC}_{50}$ value of $97 \pm 18 \mu \mathrm{M}$ [116]. Furthermore, incubation of HT29 cells with high concentration of genistein $(200 \mu \mathrm{M})$ resulted in a significant decrease of HDAC1 protein. Similar results were obtained on human esophageal squamous cell carcinoma cells KYSE 510, in which $5 \mu \mathrm{M}$ and $100 \mu \mathrm{M}$ genistein inhibited $13.2 \%$ and 33\% of HDAC activity, respectively [101].

Genistein was also observed to decrease expression of HDACs in other types of cells, as well. In aforementioned human breast cancer cell lines, MCF-7 and MDA-MB-231, genistein treatment (15 and $10 \mu \mathrm{M}$ ) induced reduction ( 2 and $\sim 4$ fold, respectively) in expression of HDAC1 protein [117]. Genistein $(25 \mu \mathrm{M})$ has been reported to significantly downregulate expression of class II HDAC6 protein in prostate cancer cells, LNCaP [100]. Since HDAC6 is a Hsp90 deacetylase, such a change leads to an increase in the acetylated form of Hsp90 and hence inhibition of its chaperone activity. The consequence of the lack of the chaperone function is ubiquitin-mediated degradation of androgen receptor protein. However, in difference to its structural isomer apigenin (Table 1), genistein does not modulate activity of recombinant SIRT6 [72].

In addition to its impact on histone acetylation and methylation, genistein was also shown to influence DNMTs in vitro, at the transcriptional level and also through inhibition of DNMT1 activity $[117,118]$. It reduces methylation specifically at promoters of tumor suppressor genes thus affecting cancer cell survival [101]. In KYSE 510 cells treated with 2-20 $\mu \mathrm{M}$ genistein, the inhibition of DNMT1 activity was associated with demethylation of the CpG islands specifically in the promoters of $p 16, R A R-\beta$ (retinoic acid receptor beta) and MGMT (O6-methylgua- 
nine methyltransferase) resulting in their consequential transcriptional reactivation [101,118]. Because genistein is a weak inhibitor of DNMTs, it does not induce global genomic hypomethylation but selective hypomethylation at hypermethyated region of genomic DNA, corresponding to aforementioned tumor suppressor genes, $p 21$ and $p 16$ [117].

Genistein can restore the expression of genes silenced by DNA hypermethylation in breast cancers not only by inhibiting enzymatic activity of DNMT1, but also through decrease of DNMT1 protein level [117]. Increased expression of DNMT1, DNMT3a, and DNMT3b is common in various cancer types, including breast cancer. Treatment of MCF-7 and MDAMB-231 cell lines with genistein (as well as with other polyphenolic DNMT1 inhibitors, EGCG or curcumin), resulted in a significant decrease not only of HDAC1, but also of DNMT1 and $\mathrm{MeCP} 2$ protein levels, joined with a significant decrease in the transcript levels of all three DNMTs-DNMT1, DNMT3a, and DNMT3b [117]. The genistein effects on cell viability of these breast cancer cells were dose-dependent with $\mathrm{IC}_{50}$ values of 15 and $10 \mu \mathrm{M}$ for MCF-7 and MDAMB-231cells, respectively.

The inhibitory effects of genistein on DNMTs and HDACs may have an intrinsic synergistic effect [101]. Genistein has been observed to have additive effects on the reactivation of methylation-silenced genes in combination with other DNMT inhibitor decitabine or a HDAC inhibitor trichostatin A [101].

\section{EGCG}

The (-)-epigallocatechin-3-O-gallate (EGCG) is the most abundant catechin in green tea, accounting for $50-70 \%$ of green tea catechins [119]. Other green tea catechins are (-)-epigallocatechin (EGC), (-)-epicatechin-3-gallate (ECG) and (-)-epicatechin (EC).

EGCG is a strong free radical scavenger [59]. Its antioxidant activity is additionally enhanced by induction of expression of phase II detoxifying and antioxidant enzymes such as glutathione S-transferases (GST), glutathione peroxidase (GPx), glutamate cysteine ligase (GCL), heme oxygenase-1 (HO-1) and many other enzymes involved in the elimination or inactivation of reactive oxygen species (ROS) and electrophiles implicated in multi-stage carcinogenesis. EGCG acts through Nrf2/ARE dependant way via activated Akt and ERK1/2 signaling and / or through modifying cysteine thiols of Keap1 (Kelch-like ECH-associated protein 1), a repressor of Nrf2 [120]. EGCG can also inhibit carcinogenesis by modulating some other transduction pathways including JAK/STAT, Wnt and Notch [57,121]. EGCG-induced inhibition of EGFR (epidermal growth factor receptor) pathway is well-documented. It also negatively influences topoisomerase II [122]. In majority cancer cell lines tested so far, this catechin induces G0/G1 phase cell cycle arrest. Finally, EGCG induces apoptosis through both, p53-dependent and p53-independent pathways. These activities, joined with an inhibitory effect on NF- $\kappa B$ and MMPs, leads also to inhibition of angiogenesis, invansion and metastasis formation $[119,121]$. In addition to all these processes, chemopreventive and anticancer effects of EGCG are also based on modifications of epigenetic processes, selectively in the cancer cells. In vitro studies show that EGCG enters cellular nuclei and binds to both DNA and RNA [122]. 
As already stated, DNA methylation patterns and histone modifications significantly differ between normal and tumor cells. Accordingly, selective targeting of epigenetic marks that makes the difference between these two kinds of cells is a challenge in cancer therapy. In cancer prevention, selective "preservance" of protective epigenetic marks represents an imperative that deserves specific attention. In the field of therapy, reexpression of DNA methylationsilenced tumor suppressor genes by inhibiting the DNMTs (DNMT1, DNMT3A, and DNMT3B) has emerged as an effective strategy [123].

EGCG is a natural non-nucleoside inhibitor of DNMT1, undergoing clinical testing [124]. DNMT1 is overexpressed in the S-phase of cell cycle, particularly in highly proliferating cells, which are the basic feature of cancer. This enzyme has a high preference for hemimethylated DNA and is essential for maintaining the methylation pattern during each round of DNA replication. Strong inhibitory effect of EGCG with $\mathrm{IC}_{50}$ at $0.47 \mu \mathrm{M}$ on human DNMT1-mediated DNA methylation was independent of the COMT-mediated methylation of EGCG (Figure 2) [78]. EGCG inhibits activity of the DNMT1 molecule directly by binding to its catalytic site through formation of $\mathrm{H}$-bonds [78,125,126]. This binding is stabilized by $\mathrm{Mg}^{2+}$ ions [78]. The galloyl moiety was shown to most considerably contribute to high-affinity of EGCG for human DNMT1. Thus, DNMT1 is also directly inhibited by other polyphenols with galloyl or also pyrogallic acid (e.g. myricetin) moiety [78].

In breast cancer cell lines MCF-7 and MDB-MB-231 EGCG, like genistein and also curcumin, downregulates transcription of not only DNMT1, but also de novo DNMTs, DNMT3a, and DNMT3b. The effect extends to the proteins, lowering the level of DNMT1, HDAC1, and $\mathrm{MeCP} 2$, known to interact with methylated DNA CPG regions [117]. Its effects on MCF-7 and MDB-MB-231 cell viability were dose-dependent with $\mathrm{IC}_{50}$ of 10 and $15 \mu \mathrm{M}$, respectively.

Similarly to genistein, EGCG may, in physiologically attainable concentrations, reverse aberrant gene hypermethylation $[101,118,126]$. In vitro demethylation of specific promoters has been shown in various cancer cell types for many genes including $p 16, M G M T, h M L H 1$ (human mutL homologue 1), GSTP1 (Glutathione S-transferase Pi) and/or RAR $3[118,126]$. Epigenetic silencing of a phase II enzyme GSTP1 has been recognized as a molecular hallmark of human prostate cancer. Exposure of human prostate wild-type p53 cancer cell lines, LNCaP and MDA PCa $2 \mathrm{~b}$, to green tea polyphenols and EGCG alone $(5-20 \mu \mathrm{M})$ for several days caused a concentration-and time-dependent reactivation of this enzyme, through extensive demethylation in the proximal GSTP1 promoter and regions distal to the transcription factor binding sites. This specific action of green tea polyphenols was correlated with the inhibition of both, DNMT1 expression and activity [127]. Of importance, exposure of LNCaP cells to green tea polyphenols did not result in global hypomethylation, but, instead, promoted maintenance of genomic integrity. Additionally, the exposure of LNCaP cells to EGCG reduced transcriptional activity of genes coding for HDACs 1-3 which also resulted with their decrease at the protein levels. This molecular change was joined with the increased level of acetylated histones $\mathrm{H} 3$ (H3K9 and H3K18) and H4.

In the context of uniqueness of cellular epigenome, in human epidermoid carcinoma cells A431 the EGCG $(5-20 \mu \mathrm{M})$ treatment did decrease global DNA methylation level. Expectedly, it was joined with decrease of DNMT1 transcript, protein and enzymatic activity in a dose-dependent manner, although far less than upon the treatment with clinically approved demethylating 
drug decitabine $(5 \mu \mathrm{M})$ [128]. In this model, EGCG treatment resulted in re-expression of the mRNA and proteins of silenced tumor suppressor genes $p 16$ and $p 21$. There was also an increase in histones H3 (H3K9 and H3K14) and H4 (H4K5, H4K12, H4K16) acetylation and decrease in level of methylated H3K9. These phenomena were ascribed to decreased level of HDAC activity in A431 cells upon EGCG treatment [128].

In pancreatic metastatic adenocarcinoma cells AsPC-1, EGCG $(10 \mu \mathrm{M})$ was also shown to induce Raf kinase inhibitor protein (RKIP) via, in part, the inhibition of HDAC activity [129]. At the same time, this treatment repressed activation of ERK and upregulated E-cadherin expression. Histone $\mathrm{H} 3$ expression was also increased, while Snail (zinc finger protein SNAI1) expression, NF- $\kappa B$ nuclear translocation and MMP-2 and-9 activities were inhibited. Of great importance, the treatment decreased metastatic potential of these cells.

Inhibition of HDAC activity and HDAC1 protein expression was recorded in a model of human colon carcinoma, HT29 [116]. EGCG at concentration $100 \mu \mathrm{M}$, inhibited HDAC activity by about $50 \%$. Concomitantly, a significant decrease of the HDAC1 protein level was observed depending on EGCG concentration (significant reduction at concentrations $\geq 50 \mu \mathrm{M}$ ).

EGCG mediated, dose-and time-dependent inhibition of class I HDACs (HDAC1, 2, 3 and 8) joined with the increased acetylation of histone $\mathrm{H} 3$ and p53, were shown in experiments that were performed on prostate cancer cell lines LNCaP and PC-3 [130]. Acetylation of p53 resulted in its binding to the promoters of $p 21$ and BAX genes leading to increased accumulation of cells in the G0/G1 cell cycle phase and induction of apoptosis. Acetylation of p53 at Lys373 and Lys382 results in p53 accumulation due to block of its MDM-2 mediated ubiquitination [130]. Finally, EGCG was suggested to contribute also to proteasomal degradation of class I HDACs [130].

Similar to quercetin, EGCG and polyphenols with the galloyl moiety in general, stimulate the activity of recombinant SIRT1 enzyme under stabilizing antioxidant conditions (achieved by adding vitamin C or catalase) [67]. Without stabilization, recombinant SIRT1 became a target for strong inhibition by these polyphenols [49], probably due to their auto-oxidation and $\mathrm{H}_{2} \mathrm{O}_{2}$ formation [67]. These data point to the importance of testing in vitro stability of polyphenol aglycons and tentative effects of actual products of their (bio)chemical transformations. For example, quercetin did not show any effect on the deacetylation activity of SIRT1 in HT29 cells [67].

In addition to its influence on HDACs, EGCG has been identified as a specific inhibitor of majority of HATs [131]. In HeLa cell nuclear extract, EGCG at $100 \mu \mathrm{M}$ concentration inhibited $90 \%$ of HAT activity while no changes in total HDAC, SIRT1 and histone methyltransferase activities were observed. The observed inhibitory action on NF- $\kappa$ B activation by EGCG has been ascribed to its inhibition of RelA (p65) acetylation rather than the direct inhibition of p65 phosphorylation. The mechanism was explained using HEK293 cells in which EGCG $(100 \mu \mathrm{M})$ abrogated p300-induced p65 acetylation. Hypoacetylation of p65 increases the level of cytosolic I $\kappa \mathrm{B} \alpha$ which prevents p65 translocation into the nucleus, thus interrupting the TNF $\alpha-$ induced cascade of events.

EGCG $(50 \mu \mathrm{M})$ inhibitory effect on HATs may be beneficial in hormone dependent prostate cancer due to suppression of agonist-dependent androgen receptor (AR) activation by 
downregulation of its acetylation. Consequentially, AR remains "locked" in the cytoplasm and cannot activate AR-related gene transcription [132]. Like p65, androgen receptor is also acetylated by p300/CBP and PCAF (HAT KAT2B)/TIP60 (HAT KAT5), supporting the hypothesis that HAT coactivators compete with HDAC corepressors for binding to promoter regions and/or protein substrates and determine the level of transcription.

\section{Curcumin}

Curcumin (1,7-bis(4-hydroxy-3-methoxy-phenyl)-1,6-heptadiene-3,5-dione) is a natural yellow-coloured curcumoid whose medicinal properties have long been recognized in traditional Indian Ayurvedic medicine [133]. This chemical is an important part of curry spice mix. It was brought to Western world in the 14th century.

Like other well-known polyphenols, curcumin has diverse pharmacological properties including chemopreventive activity [134]. Its proven antioxidative, anti-inflammatory, antiproliferative and antiangiogenic effects brought it in the focus for use in cancer prevention. Recently its impact on cell signal transduction pathways by regulation expression and/or activity of various proteins including NF- $\kappa$ B, Akt, MAPK, p53, Nrf2, Notch-1, JAK/STAT, $\beta-$ catenin, and AMPK (5'-AMP-activated protein kinase) has been reviewed [135]. Curcumin induces growth arrest at G1 or G2/M phase of cell cycle leading to apoptosis of cancer cells of various types. Indeed, if one molecule has an influence on all these processes, then it has to be that it triggers basic biochemical processes in the cell.

Pharmacokinetic analyses have shown that its concentration in human plasma is far below concentrations measured in experimental cell culture systems [136]. The most likely explanation for its observed biological activity may be related to the possibility that curcumin exerts its biological activity through remodeling the epigenome network. If this kind of action indeed takes the place, one would expect that lower concentrations are required for various biological actions.

Indeed, curcumin is a strong modulator of epigenome [137]. It reduces histone acetylation mainly via inhibition of HAT activity $[138,139]$. Its first epigenome-modifying activity was shown in 2004 through its specific inhibition of acetyltransferase activity of p300/CBP in cervical cancer cells, HeLa [138]. The consequence of this event was acetylation inhibition of histones $\mathrm{H} 3$ and $\mathrm{H} 4$ with $\mathrm{IC}_{50} \sim 25 \mu \mathrm{M}$. This effect was specific since the HAT activity of PCAF, histone deacetylase HDAC1 and histone methyltransferases remains unchanged. Curcumin binding to the active site of p300 also abolished p300-mediated acetylation of p53. This may be of great importance because p300/CBP directly interacts with and acetylates p53, enhances its transcriptional activation ability and, consequently, DNA repair. However, due to the fact that $\mathrm{p} 53$ can be target of other HATs that are not inhibited by curcumin, its acetylation status upon curcumin treatment remained in the physiological range.

Curcumin's HAT p300/CBP inhibitory activity is based on its Michael reaction acceptor functionality where its $\alpha, \beta$ unsaturated carbonyl groups in the linker (Table 1 ) act as reaction sites [140]. Its binding to $\mathrm{p} 300 / \mathrm{CBP}$ induces conformational changes which result in decreased binding afinities of histones and acetyl CoA for p300 [138]. Curcumin has also been reported 
to promote proteasome-dependent degradation of p300 and CBP without affecting the HATs PCAF or GCN5 [140].

HAT inhibition may be a base for a variety of pharmacological effects of curcumin. HATs, have been implicated in cancer cell growth and survival, and as such, HATs represent therapeutically relevant molecular targets for anticancer drug development. HAT inhibitors also seem promising for the treatment of Alzheimer's disease and diabetes [141]. As a co-activator, p300/ CBP also enhances NF- $\kappa B$ transcriptional activity by acetylating NF- $\kappa B / p 65$ as well as surrounding histones. Direct inhibition and downregulation of p300/CBP therefore contribute to the inhibition of NF- $\kappa B$ by curcumin. Curcumin's influence on NF- $\kappa B$ activity is extremely important for its chemopreventive potency [142]. Additionally, its anti-infectious activities against HIV-1 [138] and Plasmodium falciparum [143] can also arise from inhibition of HAT activity.

In addition, on HeLa nuclear extracts curcumin showed the potent activity as an inhibitor of HDAC [144]. At a very high concentration of $500 \mu \mathrm{M}$, curcumin was found to reduce $\sim 50 \%$ HDAC activity and its $\mathrm{IC}_{50}$ was $115 \mu \mathrm{M}$. In the cited study, the design of the experiment did not allow for any conclusion on the mechanism of inhibition: inhibitor candidates were mixed with HeLa nuclear extract before addition of HDAC fluorometric substrate which was sensitized through deacetylation and fluorescence. Hence, only the consequence of the presence of potential inhibitor was measured. In leukemia cell lines curcumin was shown to increase expression of suppressors of cytokine signaling, SOCS1 and SOCS3, through global inhibition of HDAC activity and decreased expression of HDAC8 [145]. In curcumin ( $25 \mu \mathrm{M}$, $24 \mathrm{~h}$ ) treated Raji cells (Epstein-Barr virus transformed lymphocyte), a decrease of HDAC8 was joined with similar levels of decrease of HDACs 1 and 3, leading to significant increase of histone H4 acetylation [146]. Curcumin was also shown to reduce HDAC activity in medulloblastoma cells and directly inhibits transcription of HDAC4 [147]. These results represent an extension of previous scientific work showing that curcumin's free binding energy and inhibition constant for HDAC8 are comparable to trichostatin A and vorinostat [144].

Like luteolin, quercetin and resveratrol, curcumin $(50 \mu \mathrm{M})$ inhibits histone demethylase activity of recombinant LSD1 [76].

Curcumin can induce epigenetic modifications by modulating not only histone acetylation but also DNA methylation. It is considered to be a hypomethylating agent decreasing DNMT activity $[137,148]$. Similarly to genistein and EGCG, curcumin $(10 \mu \mathrm{M})$ has been demonstrated to have the potential to reverse the epigenetic changes in breast cancer cells through inducing significant decrease in protein levels of DNMT1, HDAC1 and MeCP2 as well as in the transcript levels of all three DNMTs, DNMT1, DNMT3a and DNMT3b [117]. Curcumin has been found to covalently block the catalytic thiol group within catalytic site of DNMT1 with an $\mathrm{IC}_{50}$ of only $3 \mu \mathrm{M}$ after $72 \mathrm{~h}$ treatment, leading to reduction of DNA methylation by $15-20 \%$, as shown in the model of AML cell line MV4-11 [148]. Curcumin treatment decreased the mRNA and protein levels of DNMT1 and downregulated its DNA methylation activity in breast cancer cells MCF-7. The downregulation of DNMT1 mRNA may well be a consequence of lack of an $\mathrm{NF}-\kappa \mathrm{B} / \mathrm{Sp} 1$ binding to the promoter region of DNMT1 [149]. Both proteins are shown to bind to DNMT1 promoter and positively regulate DNMT1 expression. Thus, in curcumin treated 
cells, a decrease of NF- $\kappa \mathrm{B}$ and Sp1-well known curcumin targets, may directly influence the activity of DNMT1 gene.

The most recent findings indeed confirm that curcumin decreases DNMT1 expression not only in various leukemia cell lines, but also in patient's primary AML cells treated ex vivo [150]. This effect was concomitant with reactivation of tumor suppressor gene $p 15^{I N K 4 B}(\mathrm{p} 15)$ through hypomethylation of its promoter, G1 cell cycle arrest, and in vitro induction of apoptosis. This effect is, again, specific for transformed cells as it is absent in patient's healthy PBMCs treated in this way.

In contrast to non-specific global hypomethylation induced by decitabine, curcumin treatment of three colorectal cancer cell lines HCT116, HT29 and RKO, resulted in methylation changes at selected partially-methylated loci, instead of fully-methylated CpG site [151]. Curcumin has also been found to selectively induce demethylation of promoters of $N R F 2$ and RAR $\beta 2$ genes [152]. It also down-regulated expression of EZH2 and thus reduced H3K27me3 methylation, as shown in in MDA-MB-435 cells [153].

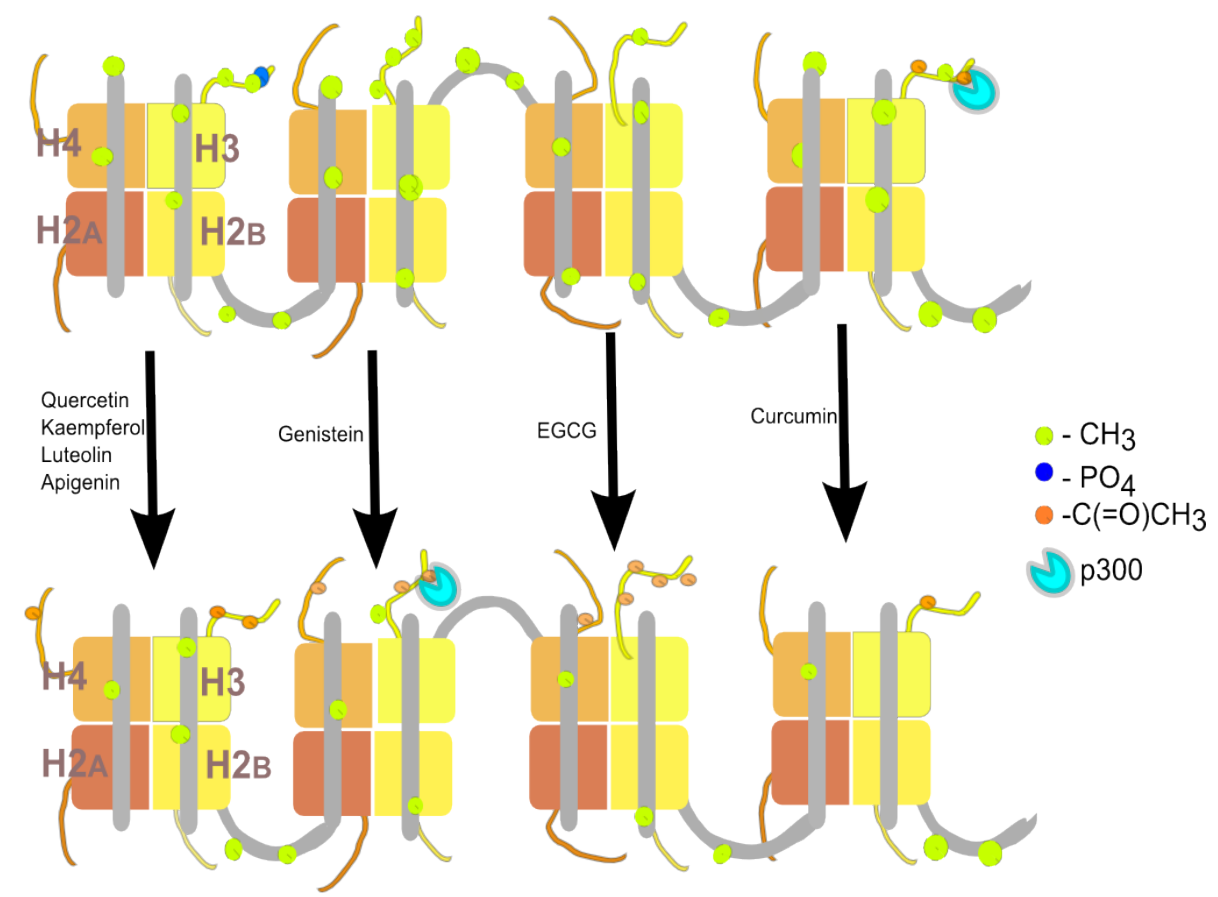

Figure 3. Epigenetic modifications induced by selected polyphenols. Molecular mechanisms of action depends upon their structures - flavonols and flavones directly inhibit histone demethylase LSD1 and indirectly DNMTs (Figure 2); genistein promotes HAT activity and DNA demethylation; EGCG is a direct DNMT inhibitor; curcumin affects many epigenome modifying enzymes. 


\section{Conclusion}

Experimental data reported so far clearly point to dietary polyphenols as potent epigenetic modulators, able to "restore" disturbed epigenomic network which is present in premalignant and malignant cells. Polyphenols usually target more than one epigenome-modulating enzyme. In the case of curcumin the effect can be extended to enzymes with antagonistic functions. This is very interesting as it opens the question related to "epigenetic balance" and "epigenetically balanced cell". With our current knowledge, we cannot predict all possible consequences of these polyvalent modes of action.

The epigenetic effects of polyphenols are largely dependent upon compound concentration, its application time window, and, very important - on a specifically established epigenome networking which is specific for each cancer cell. As xenobiotics, natural polyphenols are substrates of various metabolic enzymes. Upon cellular uptake they can be chemically transformed by various metabolic processes that depend on both, compound concentration and the type of the cell. When studying biological effects of polyphenols, their chemical characterization has to be performed in order to detect the most probably active form.

In summary, herein considered flavonoids and curcumin represent attractive starting scaffolds for design of chemopreventive or therapeutic drugs against various cancer types. In addition, due to specific effects on epigenome, they may be useful as chemical probes that may help to understand effects of natural and synthetic molecules on epigenome and chromatin remodeling.

\section{Acknowledgements}

This work was supported by Ministry of Science, Education and Sport, Republic of Croatia.

\section{Author details}

Višnja Stepanić, Renata Novak Kujundžić and Koraljka Gall Trošelj

Laboratory for Epigenomics, Ruđer Bošković Institute, Zagreb, Croatia

\section{References}

[1] Suzuki J, Chen YY, Scott GK, Devries S, Chin K, Benz CC, Waldman FM, Hwang ES. Protein acetylation and histone deacetylase expression associated with malignant breast cancer progression. Clin Cancer Res. 2009;15(9) 3163-3171. 
[2] Gall Trošelj K, Novak Kujundžić R, Grbeša I. The Importance of Aberrant DNA Methylation in Cancer. In: Tatarinova T (Ed.) DNA Methylation- From Genomics to Technology. InTech; 2012. Available from: phttp://www.intechopen.com/books/dnamethylation-from-genomics-to-technology/the-importance-of-aberrant-dna-methylation-in-cancer

[3] Bamia C, Lagiou P, Buckland G, Grioni S, Agnoli C, Taylor AJ, Dahm CC, Overvad K, Olsen A, Tjønneland A, Cottet V, Boutron-Ruault MC, Morois S, Grote V, Teucher B, Boeing H, Buijsse B, Trichopoulos D, Adarakis G, Tumino R, Naccarati A, Panico S, Palli D, Bueno-de-Mesquita HB, van Duijnhoven FJ, Peeters PH, Engeset D, Skeie G, Lund E, Sánchez MJ, Barricarte A, Huerta JM, Quirós JR, Dorronsoro M, Ljuslinder I, Palmqvist R, Drake I, Key TJ, Khaw KT, Wareham N, Romieu I, Fedirko V, Jenab M, Romaguera D, Norat T, Trichopoulou A. Mediterranean diet and colorectal cancer risk: results from a European cohort. Eur J Epidemiol. 2013;28(4) 317-328.

[4] Woodcock CL, Ghosh RP. Chromatin higher-order structure and dynamics. Cold Spring Harb Perspect Biol. 2010;2(5) a000596.

[5] Cohen I, Poreba E, Kamieniarz K, Schneider R. Histone modifiers in cancer: Friends or foes? Genes Cancer 2011;2(6) 631-647.

[6] Bannister AJ, Kouzarides T. Regulation of chromatin by histone modifications. Cell Res. 2011;21(3) 381-395.

[7] Lachner M, O'Carroll D, Rea S, Mechtler K, Jenuwein T. Methylation of histone H3 lysine 9 creates a binding site for HP1 proteins. Nature 2001;410(6824) 116-120.

[8] Baek SH. When signaling kinases meet histones and histone modifiers in the nucleus. Cell 2011;42(3) 274-284.

[9] Phillips DMP. The presence of acetyl groups in histones. Biochem J. 1963;87(2) 258-263.

[10] Allfrey V, Faulkner R, Mirsky A. Acetylation and methylation of histones and their possible role in the regulation of RNA synthesis. Proc Natl Acad Sci USA. 1964;51(5) 786-794.

[11] Zentner GE, Henikoff S. Regulation of nucleosome dynamics by histone modifications. Nat Struct Mol Biol. 2013;20(3) 259-266.

[12] Barth TK, Imhof A. Fast signals and slow marks: the dynamics of histone modifications. Trends Biochem Sci. 2010;35(11) 618-626.

[13] Islam AB, Richter WF, Lopez-Bigas N, Benevolenskaya EV. Selective targeting of histone methylation. Cell Cycle 2011;25(4) 413-424.

[14] Zhang JA, Mortazavi A, Williams BA, Wold BJ, Rothenberg EV. Dynamic transformations of genome-wide epigenetic marking and transcriptional control establish $\mathrm{T}$ cell identity. Cell 2012;149(2) 467-482. 
[15] Dillon SC, Zhang X, Trievel RC, Cheng X. The SET-domain protein superfamily: protein lysine methyltransferases. Genome Biol. 2005;6(8) 227.

[16] Shi Y, Lan F, Matson C, Mulligan P, Whetstine JR, Cole PA, Casero RA, Shi Y. Histone demethylation mediated by the nuclear amine oxidase homolog LSD1. Cell 2004;119(7) 941-953.

[17] Arita A, Shamy MY, Chervona Y, Clancy HA, Sun H, Hall MN, Qu Q, Gamble MV, Costa M. The effect of exposure to carcinogenic metals on histone tail modifications and gene expression in human subjects. J Trace Elem Med Biol. 2012;26(2-3) 174-178.

[18] Sasai N, Defossez PA. Many paths to one goal? The proteins that recognize methylated DNA in eukaryotes. Int J Dev Biol. 2009;53(2-3) 323-334.

[19] Taverna SD, Li H, Ruthenburg AJ, Allis CD, Patel DJ. How chromatin-binding modules interpret histone modifications: lessons from professional pocket pickers. Nat Struct Mol Biol. 2007;14(11) 1025-1040.

[20] Ruthenburg AJ, Li H, Patel DJ, Allis CD. Multivalent engagement of chromatin modifications by linked binding modules. Nat Rev Mol Cell Biol. 2007;8(12) 983-994.

[21] Rajendran P, Ho E, Williams DE, Dashwood RH. Dietary phytochemicals, HDAC inhibition, and DNA damage/repair defects in cancer cells. Clin Epigenetics 2011;3(1) 4.

[22] Ito A, Kawaguchi Y, Lai CH, Kovacs JJ, Higashimoto Y, Appella E, Yao TP. MDM2HDAC1-mediated deacetylation of p53 is required for its degradation. EMBO J. 2002;21(22) 6236-6245.

[23] Bojang P Jr, Ramos K. The promise and failures of epigenetic therapies for cancer treatment. Cancer Treat Rev. 2014;40(1) 153-169.

[24] Rajgolikar G, Chan KK, Wang HC. Effects of a novel antitumor depsipeptide, FR901228, on human breast cancer cells. Breast Cancer Res Treat. 1998;51(1) 29-38.

[25] Sandor V, Senderowicz A, Mertins S, Sackett D, Sausville E, Blagosklonny MV, Bates SE. P21-dependent $G_{1}$ arrest with downregulation of cyclin D1 and upregulation of cyclin E by the histone deacetylase inhibitor FR901228. Br J Cancer 2000;83(6) 817-825.

[26] Lin KT, Wang JW, Chen CT, Ho CM, Su WH, Jou YS. HDAC inhibitors augmented cell migration and metastasis through induction of PKCs leading to identification of low toxicity modalities for combination cancer therapy. Clin Cancer Res. 2012;18(17) 4691-4701.

[27] Orlikova B, Diederich M. Power from the garden: plant compounds as inhibitors of the hallmarks of cancer. Curr Med Chem. 2012;19(14) 2061-2087.

[28] Reuter S, Gupta SC, Park B, Goel A, Aggarwal BB. Epigenetic changes induced by curcumin and other natural compounds. Genes Nutr. 2011;6(2) 93-108. 
[29] Suzuki T, Miyata N. Lysine demethylases inhibitors. J Med Chem. 2011;54(24) 8236-8250.

[30] Szarc vel Szic K, Palagani A, Hassannia B, Sabbe L, Heyninck K, Haegeman G, Berghe WV. Phytochemicals and Cancer Chemoprevention: Epigenetic Friends or Foe? In: Iraj Rasooli (Ed.), Phytochemicals - Bioactivities and Impact on Health. InTech; 2011 Available from: http://www.intechopen.com/books/phytochemicals-bioactivities-and-impact-on-health/phytochemicals-and-cancer-chemopreventionepigenetic-friends-or-foe-

[31] Spencer JP, Abd-el-Mohsen MM, Rice-Evans C. Cellular uptake and metabolism of flavonoids and their metabolites: implications for their bioactivity. Arch Biochem Biophys. 2004;423(1) 148-161.

[32] Psahoulia FH, Drosopoulos KG, Doubravska L, Andera L, Pintzas A. Quercetin enhances TRAIL-mediated apoptosis in colon cancer cells by inducing the accumulation of death receptors in lipid rafts. Mol Cancer Ther. 2007;6(9) 2591-2599.

[33] Hironori T. Structure-dependent membrane interaction of flavonoids associated with their bioactivity. Food Chem. 2010;120(4) 1089-1096.

[34] Granado-Serrano AB, Martín MA, Bravo L, Goya L, Ramos S. Quercetin modulates Nrf2 and glutathione-related defenses in HepG2 cells: Involvement of p38. Chem Biol Interact. 2012;195(2) 154-164.

[35] Mukai R, Terao J, Shirai Y, Saito N, Ashida H. Determination of Subcellular Localization of Flavonol in Cultured Cells by Laser Scanning. In: Chau-Chang Wang (Ed.) Laser Scanning, Theory and Applications, InTech; 2011. Available from: http:// www.intechopen.com/books/laser-scanning-theory-and-applications/determinationof-subcellularlocalization-of-flavonol-in-cultured-cells-by-laser-scanning

[36] Sharma H, Gupta S. Sub-cellular distribution and antioxidant potential of plant flavonoid apigenin. In: Proceedings of the $102^{\text {nd }}$ Annual Meeting of the American Association for Cancer Research; 2-6 Apr 2011, Orlando, FL. Philadelphia (PA): AACR; Cancer Res. 2011;71(8 Suppl):Abstract nr 4632.

[37] Mukai R, Shirai Y, Saito N, Yoshida K, Ashida H. Subcellular localization of flavonol aglycone in hepatocytes visualized by confocal laser scanning fluorescence microscope. Cytotechnology 2009;59(3) 177-182.

[38] Kunwar A, Barik A, Mishra B, Rathinasamy K, Pandey R, Priyadarsini KI. Quantitative cellular uptake, localization and cytotoxicity of curcumin in normal and tumor cells. Biochim Biophys Acta 2008;1780(4) 673-679.

[39] Han DW, Matsumura K, Kim B, Hyon SH. Time-dependent intracellular trafficking of FITC-conjugated epigallocatechin-3-O-gallate in L-929 cells. Bioorg Med Chem. 2008;16(22) 9652-9659. 
[40] Piyaviriyakul S, Shimizu K, Asakawa T, Kan T, Siripong P, Oku N. Anti-angiogenic activity and intracellular distribution of epigallocatechin-3-gallate analogs. Biol Pharm Bull. 2011;34(3) 396-400.

[41] Gu L, Laly M, Chang HC, Prior RL, Fang N, Ronis MJ, Badger TM. Isoflavone conjugates are underestimated in tissues using enzymatic hydrolysis. J Agric Food Chem. 2005;53(17) 6858-6863.

[42] Thakur VS, Gupta K, Gupta S. The chemopreventive and chemotherapeutic potentials of tea polyphenols. Curr Pharm Biotechnol. 2012;13(1) 191-199.

[43] Hong J, Lu H, Meng X, Ryu JH, Hara Y, Yang CS. Stability, cellular uptake, biotransformation, and efflux of tea polyphenol (-)-epigallocatechin-3-gallate in HT-29 human colon adenocarcinoma cells. Cancer Res. 2002;62(24) 7241-7246.

[44] Breinholt VM, Offord EA, Brouwer C, Nielsen SE, Brøsen K, Friedberg T. In vitro investigation of cytochrome P450-mediated metabolism of dietary flavonoids. Food Chem Toxicol. 2002;40(5) 609-616.

[45] Salucci M, Stivala LA, Maiani G, Bugianesi R, Vannini V. Flavonoids uptake and their effect on cell cycle of human colon adenocarcinoma cells (Caco2). Br J Cancer 2002;86(10) 1645-1651.

[46] Zhu Y, Chiang H, Zhou J, Xie F and Kissinger P T. In vitro metabolism study of resveratrol and identification and determination of its main metabolite piceatannol by LC/EC and LC/MS/MS. Asian J Drug Metab Ph. 2005;5(1) 49-54.

[47] Gradolatto A, Canivenc-Lavier MC, Basly JP, Siess MH, Teyssier C. Metabolism of apigenin by rat liver phase I and phase II enzymes and by isolated perfused rat liver. Drug Metab Dispos. 2004;32(1) 58-65.

[48] Spencer JPE, Kuhnle GG, Williams RJ, Rice-Evans C. Intracellular metabolism and bioactivity of quercetin and its in vivo metabolites. Biochem J. 2003;372(Pt 1) 173-181.

[49] Beekmann K, Actis-Goretta L, van Bladeren PJ, Dionisi F, Destaillats F, Rietjens IM. A state-of-the-art overview of the effect of metabolic conjugation on the biological activity of flavonoids. Food Funct. 2012;3(10) 1008-1018.

[50] Son TG, Camandola S, Mattson MP. Hormetic dietary phytochemicals. Neuromolecular Med. 2008;10(4) 236-246.

[51] Vargas AJ, Burd R. Hormesis and synergy: pathways and mechanisms of quercetin in cancer prevention and management. Nutr Rev. 2010;68(7) 418-428.

[52] Novak Kujundzić R, Grbesa I, Ivkić M, Katdare M, Gall-Troselj K. Curcumin downregulates H19 gene transcription in tumor cells. J Cell Biochem. 2008;104(5) 1781-1792. 
[53] Pietrocola F, Mariño G, Lissa D, Vacchelli E, Malik SA, Niso-Santano M, Zamzami N, Galluzzi L, Maiuri MC, Kroemer G. Pro-autophagic polyphenols reduce the acetylation of cytoplasmic proteins. Cell Cycle 2012;11(20) 3851-3860.

[54] Mukhtar E, Adhami VM, Khan N, Mukhtar H. Apoptosis and autophagy induction as mechanism of cancer prevention by naturally occurring dietary agents. Curr Drug Targets 2012;13(14) 1831-1841.

[55] Gossner G, Choi M, Tan L, Fogoros S, Griffith KA, Kuenker M, Liu JR. Genistein-induced apoptosis and autophagocytosis in ovarian cancer cells. Gynecol Oncol. 2007;105(1) 23-30.

[56] Casagrande F, Darbon JM. Effects of structurally related flavonoids on cell cycle progression of human melanoma cells: regulation of cyclin-dependent kinases CDK2 and CDK1. Biochem Pharmacol. 2001;61(10) 1205-1215.

[57] Surh YJ. (2003) Cancer chemoprevention with dietary phytochemicals. Nature Reviews Cancer 2003;3(10) 768-780.

[58] Hanahan D, Weinberg RA. Hallmarks of cancer: the next generation. Cell 2011;144(5) 646-674.

[59] Cai YZ, Mei Sun, Jie Xing, Luo Q, Corke H. Structure-radical scavenging activity relationships of phenolic compounds from traditional Chinese medicinal plants. Life Sci. 2006;78(25) 2872-2888.

[60] Yamashita N, Kawanishi S. Distinct mechanisms of DNA damage in apoptosis induced by quercetin and luteolin. Free Radic Res. 2000;33(5) 623-633.

[61] Russo GL, Russo M, Spagnuolo C, Tedesco I, Bilotto S, Iannitti R, Palumbo R. Quercetin: A pleiotropic kinase inhibitor against cancer. Cancer Treat Res. 2014;159 185-205.

[62] Boly R, Gras T, Lamkami T, Guissou P, Serteyn D, Kiss R, Dubois J. Quercetin inhibits a large panel of kinases implicated in cancer cell biology. Int J Oncol. 2011;38(3) 833-842.

[63] Xiao X, Shi D, Liu L, Wang J, Xie X, Kang T, Deng W. Quercetin suppresses cyclooxygenase-2 expression and angiogenesis through inactivation of p300 signaling. PLoS One 2011;6(8):e22934.

[64] Mutoh M, Takahashi M, Fukuda K, Matsushima-Hibiya Y, Mutoh H, Sugimura T, Wakabayashi K. Suppression of cyclooxygenase-2 promoter-dependent transcriptional activity in colon cancer cells by chemopreventive agents with a resorcin-type structure. Carcinogenesis 2000;21(5) 959-963.

[65] Ruiz PA, Braune A, Hölzlwimmer G, Quintanilla-Fend L, Haller D. Quercetin inhibits TNF-induced NF- $\kappa B$ transcription factor recruitment to proinflammatory gene promoters in murine intestinal epithelial cells. J Nutr. 2007;137(5) 1208-1215. 
[66] Chan ST, Yang NC, Huang CS, Liao JW, Yeh SL. Quercetin enhances the antitumor activity of trichostatin A through upregulation of p53 protein expression in vitro and in vivo. PLoS One 2013;8(1):e54255.

[67] de Boer VC, de Goffau MC, Arts IC, Hollman PC, Keijer J. SIRT1 stimulation by polyphenols is affected by their stability and metabolism. Mech Ageing Dev. 2006;127(7) 618-627.

[68] Hong KS, Park JI, Kim MJ, Kim HB, Lee JW, Dao TT, Oh WK, Kang CD, Kim SH. Involvement of SIRT1 in hypoxic down-regulation of c-Myc and $\beta$-catenin and hypoxic preconditioning effect of polyphenols. Toxicol Appl Pharmacol. 2012;259(2) 210-218.

[69] Anastasiou D, Krek W. SIRT1: linking adaptive cellular responses to aging-associated changes in organismal physiology. Physiology (Bethesda) 2006;21(6) 404-410.

[70] Cohen HY, Lavu S, Bitterman KJ, Hekking B, Imahiyerobo TA, Miller C, Frye R, Ploegh H, Kessler BM, Sinclair DA. Acetylation of the $\mathrm{C}$ terminus of Ku70 by CBP and PCAF controls Bax-mediated apoptosis. Mol Cell 2004;13(5) 627-638.

[71] Yeung F, Hoberg JE, Ramsey CS, Keller MD, Jones DR, Frye RA, Mayo MW. Modulation of NFKB-dependent transcription and cell survival by the SIRT1 deacetylase. EMBO J. 2004;23(12) 2369-2380.

[72] Singh N, Ravichandran S, Norton DD, Fugmann SD, Moaddel R. Synthesis and characterization of a SIRT6 open tubular column: predicting deacetylation activity using frontal chromatography. Anal Biochem. 2013;436(2) 78-83.

[73] Lee WJ, Chen YR, Tseng TH. Quercetin induces FasL-related apoptosis, in part, through promotion of histone H3 acetylation in human leukemia HL-60 cells. Oncol Rep. 2011;25(2) 583-591.

[74] Jia J, Chen J. Histone hyperacetylation is involved in the quercetin-induced human leukemia cell death. Pharmazie 2008;63(5) 379-383.

[75] Tan S, Wang C, Lu C, Zhao B, Cui Y, Shi X, Ma X. Quercetin is able to demethylate the $p 16^{\mathrm{INK} 4 \mathrm{a}}$ gene promoter. Chemotherapy 2009;55(1) 6-10.

[76] Abdulla A, Zhao X, Yang F. Natural polyphenols inhibit lysine-specific demethylase-1 in vitro. J Biochem Pharmacol Res. 2013;1(1) 56-63.

[77] Chen Y, Jie W, Yan W, Zhou K, Xiao Y. Lysine-specific histone demethylase 1 (LSD1): A potential molecular target for tumor therapy. Crit Rev Eukaryot Gene Expr. 2012;22(1) 53-59.

[78] Lee WJ, Shim JY, Zhu BT. Mechanisms for the inhibition of DNA methyltransferases by tea catechins and bioflavonoids. Mol Pharmacol. 2005;68(4) 1018-1030.

[79] Calderón-Montaño JM, Burgos-Morón E, Pérez-Guerrero C, López-Lázaro M. A review on the dietary flavonoid kaempferol. Mini Rev Med Chem. 2011;11(4) 298-344. 
[80] Huang WW, Tsai SC, Peng SF, Lin MW, Chiang JH, Chiu YJ, Fushiya S, Tseng MT, Yang JS. Kaempferol induces autophagy through AMPK and AKT signaling molecules and causes G2/M arrest via downregulation of CDK1/cyclin B in SK-HEP-1 human hepatic cancer cells. Int J Oncol. 2013;42(6) 2069-2077.

[81] Berger A, Venturelli S, Kallnischkies M, Böcker A, Busch C, Weiland T, Noor S, Leischner C, Weiss TS, Lauer UM, Bischoff SC, Bitzer M. Kaempferol, a new nutrition-derived pan-inhibitor of human histone deacetylases. J Nutr Biochem. 2013;24(6) 977-985.

[82] Sharma V, Joseph C, Ghosh S, Agarwal A, Mishra MK, Sen E. Kaempferol induces apoptosis in glioblastoma cells through oxidative stress. Mol Cancer Ther. 2007;6(9) 2544-2553.

[83] Kang GY, Lee ER, Kim JH, Jung JW, Lim J, Kim SK, Cho SG, Kim KP. Downregulation of PLK-1 expression in kaempferol-induced apoptosis of MCF-7 cells. Eur J Pharmacol. 2009;611(1-3) 17-21.

[84] Marfe G, Tafani M, Indelicato M, Sinibaldi-Salimei P, Reali V, Pucci B, Fini M, Russo MA. Kaempferol induces apoptosis in two different cell lines via Akt inactivation, Bax and SIRT3 activation, and mitochondrial dysfunction. J Cell Biochem. 2009;106(4) 643-650.

[85] Ambrosio R, Damiano V, Sibilio A, De Stefano MA, Avvedimento VE, Salvatore D, Dentice M. Epigenetic control of type 2 and 3 deiodinases in myogenesis: role of lysine-specific demethylase enzyme and FoxO3. Nucleic Acids Res. 2013;41(6) 3551-3562.

[86] da-Silva WS, Harney JW, Kim BW, Li J, Bianco SD, Crescenzi A, Christoffolete MA, Huang SA, Bianco AC. The small polyphenolic molecule kaempferol increases cellular energy expenditure and thyroid hormone activation. Diabetes 2007;56(3) 767-776.

[87] Stepanić V, Gall Trošelj K, Lučić B, Marković Z, Amić D. Bond dissociation free energy as a general parameter for flavonoid radical scavenging activity. Food Chem. 2013;141(2) 1562-1570.

[88] Markaverich BM, Vijjeswarapu M. Multiple sites of type II site ligand (luteolin and BMHPC) regulation of gene expression in PC-3 cells. Int J Biomed Sci. 2012;8(4) 219-232.

[89] Lin Y, Shi R, Wang X, Shen HM. Luteolin, a flavonoid with potential for cancer prevention and therapy. Curr Cancer Drug Targets 2008;8(7) 634-646.

[90] López-Lázaro M. Distribution and biological activities of the flavonoid luteolin. Mini Rev Med Chem. 2009;9(1) 31-59.

[91] Bandaruk Y, Mukai R, Kawamura T, Nemoto H, Terao J. Evaluation of the inhibitory effects of quercetin-related flavonoids and tea catechins on the monoamine oxidase- 
A reaction in mouse brain mitochondria. J Agric Food Chem. 2012 60(41) 10270-10277.

[92] Han XH, Hong SS, Hwang JS, Lee MK, Hwang BY, Ro JS. Monoamine oxidase inhibitory components from Cayratia japonica. Arch Pharm Res. 2007;30(1) 13-17.

[93] Attoub S, Hassan AH, Vanhoecke B, Iratni R, Takahashi T, Gaben AM, Bracke M, Awad S, John A, Kamalboor HA, Al Sultan MA, Arafat K, Gespach C, Petroianu G. Inhibition of cell survival, invasion, tumor growth and histone deacetylase activity by the dietary flavonoid luteolin in human epithelioid cancer cells. Eur J Pharmacol. 2011;651(1-3) 18-25.

[94] Chen ZJ, Dai YQ, Kong SS, Song FF, Li LP, Ye JF, Wang RW, Zeng S, Zhou H, Jiang HD. Luteolin is a rare substrate of human catechol-O-methyltransferase favoring a para-methylation. Mol Nutr Food Res. 2013;57(5) 877-885.

[95] Xie F, Lang Q, Zhou M, Zhang H, Zhang Z, Zhang Y, Wan B, Huang Q, Yu L. The dietary flavonoid luteolin inhibits Aurora B serine/threonine kinase activity and blocks proliferation of cancer cells. Eur J Pharm Sci. 2012;46(5) 388-396.

[96] Ruela-de-Sousa RR, Fuhler GM, Blom N, Ferreira CV, Aoyama H, Peppelenbosch MP. Cytotoxicity of apigenin on leukemia cell lines: implications for prevention and therapy. Cell Death Dis. 2010;1 e19.

[97] Arango D, Parihar A, Villamena FA, Wang L, Freitas MA, Grotewold E, Doseff AI. Apigenin induces DNA damage through the PKC $\delta$-dependent activation of ATM and H2AX causing down-regulation of genes involved in cell cycle control and DNA repair. Biochem Pharmacol. 2012;84(12) 1571-1580.

[98] Seo YJ, Kim BS, Chun SY, Park YK, Kang KS, Kwon TG. Apoptotic effects of genistein, biochanin-A and apigenin on LNCaP and PC-3 cells by p21 through transcriptional inhibition of polo-like kinase-1. J Korean Med Sci. 2011;26(11) 1489-1494.

[99] Pandey M, Kaur P, Shukla S, Abbas A, Fu P, Gupta S. Plant flavone apigenin inhibits HDAC and remodels chromatin to induce growth arrest and apoptosis in human prostate cancer cells: in vitro and in vivo study. Mol Carcinog. 2012;51(12) 952-962.

[100] Basak S, Pookot D, Noonan EJ, Dahiya R. Genistein downregulates androgen receptor by modulating HDAC6-Hsp90 chaperone function. Mol Cancer Ther. 2008;7(10) 3195-3202.

[101] Fang MZ, Chen D, Sun Y, Jin Z, Christman JK, Yang CS. Reversal of hypermethylation and reactivation of $p 16^{\mathrm{INK} 4 \mathrm{a}}, R A R-\beta$, and MGMT genes by genistein and other isoflavones from soy. Clin Cancer Res. 2005;11(19 Pt 1) 7033-7041.

[102] Borrás C, Gambini J, Gómez-Cabrera MC, Sastre J, Pallardó FV, Mann GE, Viña J. Genistein, a soy isoflavone, up-regulates expression of antioxidant genes: involvement of estrogen receptors, ERK1/2, and NFאB. FASEB J. 2006;20(12) 2136-2138. 
[103] Li W, Frame LT, Hirsch S, Cobos E. Genistein and hematological malignancies. Cancer Lett. 2010;296(1) 1-8.

[104] Zhang Z, Wang CZ, Du GJ, Qi LW, Calway T, He TC, Du W, Yuan CS. Genistein induces G2/M cell cycle arrest and apoptosis via ATM/p53-dependent pathway in human colon cancer cells. Int J Oncol. 2013;43(1) 289-296.

[105] Schmidt F, Knobbe CB, Frank B, Wolburg H, Weller M. The topoisomerase II inhibitor, genistein, induces G2/M arrest and apoptosis in human malignant glioma cell lines. Oncol Rep. 2008;19(4) 1061-1066.

[106] Banerjee S, Li Y, Wang Z, Sarkar FH. Multi-targeted therapy of cancer by genistein. Cancer Lett. 2008;269(2) 226-242.

[107] Majid S, Kikuno N, Nelles J, Noonan E, Tanaka Y, Kawamoto K, Hirata H, Li LC, Zhao H, Okino ST, Place RF, Pookot D, Dahiya R. Genistein induces the $p 21^{\mathrm{WAF} 1 / \mathrm{CIP} 1}$ and $p 16^{\mathrm{INK} 4 \mathrm{a}}$ tumor suppressor genes in prostate cancer cells by epigenetic mechanisms involving active chromatin modification. Cancer Res. 2008;68(8) 2736-2744.

[108] Akiyama T, Ishida J, Nakagawa S, Ogawara H, Watanabe S, Itoh N, Shibuya M, Fukami Y. Genistein, a specific inhibitor of tyrosine specific protein kinases. J Biol Chem. 1987;262(12) 5592-5595.

[109] Lamoral-Theys D, Pottier L, Dufrasne F, Nève J, Dubois J, Kornienko A, Kiss R, Ingrassia L. Natural polyphenols that display anticancer properties through inhibition of kinase activity. Curr Med Chem. 2010;17(9) 812-825.

[110] López-Lazaro M, Willmore E, Austin CA. Cells lacking DNA topoisomerase II beta are resistant to genistein. J Nat Prod. 2007;70(5) 763-767.

[111] Markovits J, Linassier C, Fossé P, Couprie J, Pierre J, Jacquemin-Sablon A, Saucier JM, Le Pecq JB, Larsen AK. Inhibitory effects of the tyrosine kinase inhibitor genistein on mammalian DNA topoisomerase II. Cancer Res. 1989;49(18) 5111-5117.

[112] Li Y, Chen H, Hardy TM, Tollefsbol TO. Epigenetic regulation of multiple tumor-related genes leads to suppression of breast tumorigenesis by dietary genistein. PLoS One 2013;8(1) e54369.

[113] Dagdemir A, Durif J, Ngollo M, Bignon YJ, Bernard-Gallon D. Histone lysine trimethylation or acetylation can be modulated by phytoestrogen, estrogen or anti-HDAC in breast cancer cell lines. Epigenomics 2013;5(1) 51-63.

[114] Li Y, Meeran SM, Patel SN, Chen H, Hardy TM, Tollefsbol TO. Epigenetic reactivation of estrogen receptor- $\alpha$ (ER $\alpha)$ by genistein enhances hormonal therapy sensitivity in ER $\alpha$-negative breast cancer. Mol Cancer. 2013;12 9.

[115] Meeran SM, Patel SN, Li Y, Shukla S, Tollefsbol TO. Bioactive dietary supplements reactivate ER expression in ER-negative breast cancer cells by active chromatin modifications. PLoS One 2012;7(5) e37748. 
[116] Groh IA, Chen C, Lüske C, Cartus AT, Esselen M. Plant polyphenols and oxidative metabolites of the herbal alkenylbenzene methyleugenol suppress histone deacetylase activity in human colon carcinoma cells. J Nutr Metab. 2013;2013 821082.

[117] Mirza S, Sharma G, Parshad R, Gupta SD, Pandya P, Ralhan R. Expression of DNA methyltransferases in breast cancer patients and to analyze the effect of natural compounds on DNA methyltransferases and associated proteins. J Breast Cancer 2013;16(1) 23-31.

[118] Fang M, Chen D, Yang CS. Dietary polyphenols may affect DNA methylation. J Nutr. 2007;137(1 Suppl) 223S-228S.

[119] Thakur VS, Gupta K, Gupta S. The chemopreventive and chemotherapeutic potentials of tea polyphenols. Curr Pharm Biotechnol. 2012;13(1) 191-199.

[120] Na HK, Surh YJ. Modulation of Nrf2-mediated antioxidant and detoxifying enzyme induction by the green tea polyphenol EGCG. Food Chem Toxicol. 2008;46(4) 1271-1278.

[121] Hou Z, Lambert JD, Chin KV, Yang CS. Effects of tea polyphenols on signal transduction pathways related to cancer chemoprevention. Mutat Res. 2004;555(1-2) 3-19.

[122] Patra SK, Rizzi F, Silva A, Rugina DO, Bettuzzi S. Molecular targets of (-)-epigallocatechin-3-gallate (EGCG): specificity and interaction with membrane lipid rafts. J Physiol Pharmacol. 2008;59(Suppl 9) 217-235.

[123] Yoo J, Medina-Franco JL. Discovery and Optimization of Inhibitors of DNA Methyltransferase as Novel Drugs for Cancer Therapy. In: Chris Rundfeldt (Ed.) Drug Development - A Case Study Based Insight into Modern Strategies. InTech; 2011. Available from: http://www.intechopen.com/books/drug-development-a-case-studybased-insight-into-modern-strategies/discovery-and-optimization-of-inhibitors-ofdna-methyltransferase-as-novel-drugs-for-cancer-therapy

[124] Schramm L. Going green: The role of the green tea component EGCG in chemoprevention. J Carcinog Mutagen. 2013;4(142) 1000142.

[125] Singh BN, Shankar S, Srivastava RK. Green tea catechin, epigallocatechin-3-gallate (EGCG): mechanisms, perspectives and clinical applications. Biochem Pharmacol. 2011;82(12) 1807-1821.

[126] Fang M, Wang Y, Ai N, Hou Z, Sun Y, Lu H, Welsh W, Yang C. Tea polyphenol (-)epigallocatechin-3-gallate inhibits DNA methyltransferase and reactivates methylation-silenced genes in cancer cell lines. Cancer Res. 2003;63(22) 7563-7570.

[127] Pandey M, Shukla S, Gupta S. Promoter demethylation and chromatin remodeling by green tea polyphenols leads to re-expression of GSTP1 in human prostate cancer cells. Int J Cancer 2010;126(11) 2520-2533.

[128] Nandakumar V, Vaid M, Katiyar SK. (-)-Epigallocatechin-3-gallate reactivates silenced tumor suppressor genes, Cip $1 / p 21$ and $p 16^{\text {INK4a }}$, by reducing DNA methylation 
and increasing histones acetylation in human skin cancer cells. Carcinogenesis 2011;32(4) 537-544.

[129] Kim SO, Kim MR. (-)-Epigallocatechin 3-gallate inhibits invasion by inducing the expression of Raf kinase inhibitor protein in AsPC-1 human pancreatic adenocarcinoma cells through the modulation of histone deacetylase activity. Int J Oncol. 2013;42(1) 349-358.

[130] Thakur VS, Gupta K, Gupta S.Green tea polyphenols increase p53 transcriptional activity and acetylation by suppressing class I histone deacetylases. Int J Oncol. 2012;41(1) 353-361.

[131] Choi KC, Jung MG, Lee YH, Yoon JC, Kwon SH, Kang HB, Kim MJ, Cha JH, Kim YJ, Jun WJ, Lee JM, Yoon HG. Epigallocatechin-3-gallate, a histone acetyltransferase inhibitor, inhibits EBV-induced B lymphocyte transformation via suppression of RelA acetylation. Cancer Res. 2009 69(2) 583-92.

[132] Lee YH, Kwak J, Choi HK, Choi KC, Kim S, Lee J, Jun W, Park HJ, Yoon HG. EGCG suppresses prostate cancer cell growth modulating acetylation of androgen receptor by anti-histone acetyltransferase activity. Int J Mol Med. 2012;30(1) 69-74.

[133] Krishnaswamy K. Traditional Indian spices and their health significance. Asia Pac J Clin Nutr. 2008;17(S1) 265-268.

[134] Kunnumakkara AB, Anand P, Aggarwal BB. Curcumin inhibits proliferation, invasion, angiogenesis and metastasis of different cancers through interaction with multiple cell signaling proteins. Cancer Lett. 2008;69(2) 199-225.

[135] Shehzad A, Lee YS. Molecular mechanisms of curcumin action: signal transduction. Biofactors 2013;39(1) 27-36.

[136] Fu S, Kurzrock R. Development of curcumin as an epigenetic agent. Cancer 2010;116(20) 4670-4676.

[137] Dicato M, Diederich M. Curcumin as a regulator of epigenetic events. Mol Nutr Food Res. 2013;57(9) 1619-1629.

[138] Balasubramanyam K, Varier RA, Altaf M, Swaminathan V, Siddappa NB, Ranga U, Kundu TK. Curcumin, a novel p300/CREB-binding protein-specific inhibitor of acetyltransferase, represses the acetylation of histone/nonhistone proteins and histone acetyltransferase-dependent chromatin transcription. J Biol Chem. 2004;279(4) 51163-51171.

[139] Kang J, Chen J, Shi Y, Jia J, Zhang Y. Curcumin induced histone hypoacetylation: the role of reactive oxygen species. Biochem Pharmacol. 2005;69(8) 1205-1213.

[140] Marcu MG, Jung YJ, Lee S, Chung EJ, Lee MJ, Trepel J, Neckers L. Curcumin is an inhibitor of p300 histone acetylatransferase. Med Chem. 2006;2(2) 169-174. 
[141] Manzo F, Tambaro FP, Mai A, Altucci L. Histone acetyltransferase inhibitors and preclinical studies. Expert Opin Ther Pat. 2009;19(6) 761-774.

[142] Chen Lf, Fischle W, Verdin E, Greene WC. Duration of nuclear NF- $\kappa B$ action regulated by reversible acetylation. Science 2001;293(5535) 1653-1657.

[143] Cui L, Miao J, Cui L. Cytotoxic effect of curcumin on malaria parasite Plasmodium falciparum: inhibition of histone acetylation and generation of reactive oxygen species. Antimicrob Agents Chemother. 2007;51(2) 488-494.

[144] Bora-Tatar G, Dayangaç-Erden D, Demir AS, Dalkara S, Yelekçi K, Erdem-Yurter H. Molecular modifications on carboxylic acid derivatives as potent histone deacetylase inhibitors: Activity and docking studies. Bioorg Med Chem. 2009;17(14) 5219-5228.

[145] Chen CQ, Yu K, Yan QX, Xing CY, Chen Y, Yan Z, Shi YF, Zhao KW, Gao SM. Pure curcumin increases the expression of SOCS1 and SOCS3 in myeloproliferative neoplasms through suppressing class I histone deacetylases. Carcinogenesis 2013;34(7) 1442-1449.

[146] Liu HL, Chen Y, Cui GH, Zhou JF. Curcumin, a potent anti-tumor reagent, is a novel histone deacetylase inhibitor regulating B-NHL cell line Raji proliferation. Acta Pharmacol Sin. 2005;26(5) 603-609.

[147] Lee SJ, Krauthauser C, Maduskuie V, Fawcett PT, Olson JM, Rajasekaran SA. Curcumin-induced HDAC inhibition and attenuation of medulloblastoma growth in vitro and in vivo. BMC Cancer 2011;11 144.

[148] Liu Z, Xie Z, Jones W, Pavlovicz RE, Liu S, Yu J, Li PK, Lin J, Fuchs JR, Marcucci G, Li C, Chan KK. Curcumin is a potent DNA hypomethylation agent. Bioorg Med Chem Lett. 2009;19(3) 706-709.

[149] Du L, Xie Z, Wu LC, Chiu M, Lin J, Chan KK, Liu S, Liu Z. Reactivation of RASSF1A in breast cancer cells by curcumin. Nutr Cancer 2012;64(8) 1228-1235.

[150] Yu J, Peng Y, Wu LC, Xie Z, Deng Y, Hughes T, He S, Mo X, Chiu M, Wang QE, He X, Liu S, Grever MR, Chan KK, Liu Z. Curcumin down-regulates DNA methyltransferase 1 and plays an anti-leukemic role in acute myeloid leukemia. PLoS One 2013;8(2) e55934.

[151] Link A, Balaguer F, Shen Y, Lozano JJ, Leung HC, Boland CR, Goel A. Curcumin modulates DNA methylation in colorectal cancer cells. PLoS One 2013;8(2) e57709.

[152] Gerhauser C. Cancer chemoprevention and nutriepigenetics: state of the art and future challenges. Top Curr Chem. 2013;329 73-132.

[153] Hua WF, Fu YS, Liao YJ, Xia WJ, Chen YC, Zeng YX, Kung HF, Xie D. Curcumin induces down-regulation of EZH2 expression through the MAPK pathway in MDAMB-435 human breast cancer cells. Eur J Pharmacol. 2010;637(1-3) 16-21. 
